\title{
The platelet to lymphocyte ratio is a potential inflammatory marker predicting the effects of adjuvant chemotherapy in patients with stage II colorectal cancer
}

Yu Fu' ${ }^{\dagger}$ Xiaowan Chen ${ }^{\dagger}$, Yongxi Song, Xuanzhang Huang, Quan Chen, Xinger LV, Peng Gao and Zhenning Wang ${ }^{*}$ (i)

\begin{abstract}
Background: The effects of adjuvant chemotherapy in patients with stage II colorectal cancer (CRC) has been in controversy for a long time. Our study aimed to find an effective inflammatory marker to predict the effects of chemotherapy.

Methods: Seven hundred eight stage II CRC patients in our institution were included. The subpopulation treatment effect pattern plot (STEPP) analysis was used to determine the optimal inflammatory marker and cut-off value. Propensity score matching (PSM) was performed to balance discrepancy between the chemotherapy and nonchemotherapy group. Survival analyses based on overall survival (OS) and cancer-specific survival (CSS) were performed with Kaplan-Meier methods with log-rank test and Cox proportional hazards regression. The restricted mean survival time (RMST) was used to measure treatment effect.

Results: The platelet to lymphocyte ratio (PLR) was chosen as the optimal marker with a cut-off value of 130 according to STEPP. In OS analysis, PLR was significantly associated with the effects of chemotherapy (interaction $p=0.027)$. In the low-PLR subgroup, the chemotherapy patients did not have a longer OS than the nonchemotherapy patients (HR: $0.983,95 \% \mathrm{Cl}$ : 0.528-1.829). In the high-PLR subgroup, the chemotherapy patients had a significantly longer OS than the non-chemotherapy patients (HR: 0.371, 95\% Cl: 0.212-0.649). After PSM, PLR was still associated with the effects of chemotherapy. In CSS analysis, PLR was not significantly associated with the effects of chemotherapy (interaction $p=0.116$ ). In the low-PLR subgroup, the chemotherapy patients did not have a longer CSS than the non-chemotherapy patients (HR: 1.016, 95\% Cl: 0.494-2.087). In the high-PLR subgroup, the chemotherapy patients had a longer CSS than the non-chemotherapy patients (HR: 0.371, 95\% Cl: 0.212-0.649). After PSM, PLR was not associated with the effects of chemotherapy.
\end{abstract}

Conclusions: PLR is an effective marker to predict the effects of chemotherapy in patients with stage II CRC. Keywords: Colorectal cancer, Stage II, Adjuvant chemotherapy, Inflammatory marker, Platelet to lymphocyte ratio

\footnotetext{
* Correspondence: gaokaji16@163.com; josieon826@sina.cn

${ }^{\dagger}$ Yu Fu and Xiaowan Chen contributed equally to this work.

Department of Surgical Oncology and General Surgery, The First Hospital of

China Medical University; Key Laboratory of Precision Diagnosis and

Treatment of Gastrointestinal Tumors (China Medical University), Ministry of

Education, 155 North Nanjing Street, Heping District, Shenyang 110001,

China
}

(C) The Author(s). 2021 Open Access This article is licensed under a Creative Commons Attribution 4.0 International License, which permits use, sharing, adaptation, distribution and reproduction in any medium or format, as long as you give appropriate credit to the original author(s) and the source, provide a link to the Creative Commons licence, and indicate if changes were made. The images or other third party material in this article are included in the article's Creative Commons licence, unless indicated otherwise in a credit line to the material. If material is not included in the article's Creative Commons licence and your intended use is not permitted by statutory regulation or exceeds the permitted use, you will need to obtain permission directly from the copyright holder. To view a copy of this licence, visit http://creativecommons.org/licenses/by/4.0/ The Creative Commons Public Domain Dedication waiver (http://creativecommons.org/publicdomain/zero/1.0/) applies to the data made available in this article, unless otherwise stated in a credit line to the data. 


\section{Background}

Colorectal cancer (CRC) is the third most commonly diagnosed cancer and the second most lethal [1]. Radical resection is the principal curative treatment for patients with nonmetastatic CRC. Adjuvant chemotherapy is a crucial means to improve additional survival benefits beyond those from surgery. Remarkably, the effects of adjuvant chemotherapy in patients with CRC is highly likely to be stage-specific. For patients with stage III CRC, adjuvant chemotherapy has been demonstrated to greatly improve survival $[2,3]$. However, survival benefits from chemotherapy in stage II CRC are still unclear. Many studies tried to find survival benefits from chemotherapy in stage II CRC but failed. In the MOSAIC study and another study based on the ACCENT database, oxaliplatin-based chemotherapy was not found to increase survival in the first 6 to 10 years after surgery [4, 5]. In the QUASAR study, the absolute improvement in survival after chemotherapy with fluorouracil was only $3.6 \%$ [6]. However, one study has demonstrated that treatment with 5-FU/LV after surgery confers significant survival benefits beyond those of surgery alone in stage II CRC [7]. On the basis of these and other studies, both the NCCN and ASCO guidelines suggest offering chemotherapy to patients with high-risk stage II CRC [8-12]. Patients are considered high-risk if they have T4 depth of invasion, peritumoral lymphatic/venous invasion, a histological grade of 3 or greater, R1-R2 margin status, bowel obstruction or perforation, elevated carcinoembryonic antigen (CEA) exceeding $5 \mathrm{ng} / \mathrm{mL}$ or fewer than 12 nodes retrieved. However, these high-risk characteristics are determined on the basis of prognosis instead of the additional survival benefit from chemotherapy. The guidelines also indicated that no available data correlated risk features and selection of chemotherapy in high-risk stage II patients [13].

In the search for characteristics predicting the effects of chemotherapy on CRC and other cancers, many inflammatory markers have been used [14-16]. Inflammatory markers including the platelet to lymphocyte ratio (PLR), neutrophil to lymphocyte ratio (NLR), lymphocyte to monocyte ratio (LMR), prognostic nutritional index (PNI) and others have been shown to be strongly associated with not only cancer prognosis [17-21], but also with chemo-resistance and chemotherapeutic responses [22-26]. Nevertheless, previous studies of inflammatory markers have focused on advanced cancers which are usually accompanied by metastasis. However, no such studies have been performed on stage II CRC.

In this study, we aimed to investigate the ability of inflammatory markers to predict the effects of chemotherapy in patients with stage II CRC and to identify an effective method allowing clinicians to distinguish the population in which chemotherapy is effective.

\section{Methods}

\section{Participants and criteria}

We retrospectively analyzed patients with stage II CRC who received surgical treatment at the Department of Surgical Oncology and General Surgery, First Affiliated Hospital of China Medical University between August 2010 and August 2015. All patients enrolled in this study had undergone radical resection (R0) for the first time. Furthermore, a portion of the patients had received adjuvant chemotherapy as a single-agent therapy regimen with fluoropyrimidines or as a combination therapy regimen with fluoropyrimidines and oxaliplatin. Patients with high-risk factors were proposed to receive chemotherapy. For patients without high-risk factors, chemotherapy reception was decided according to the will of themselves and their relatives. The single-agent therapy was comprised one of the following regimens. (1) Day 1: leucovorin $400 \mathrm{mg} / \mathrm{m}^{2}$ intravenous injection (IV), followed by a $400 \mathrm{mg} / \mathrm{m}^{2}$ IV bolus of 5 -FU, followed by $2400 \mathrm{mg} / \mathrm{m}^{2}$ as a $46-48 \mathrm{~h}$ continuous infusion. The cycle was repeated every 2 weeks for 6 months of perioperative therapy. (2) Days 1-14: capecitabine $1000-1250 \mathrm{mg} / \mathrm{m}^{2}$ orally twice daily. The cycle was repeated every 3 weeks for 6 months of perioperative therapy. The combination therapy comprised one of the following regimens. (1) Day 1: oxaliplatin $85 \mathrm{mg} / \mathrm{m}^{2}$ IV over $2 \mathrm{~h}+$ leucovorin $400 \mathrm{mg} / \mathrm{m}^{2}$ IV over $2 \mathrm{~h}$, followed a $400 \mathrm{mg} / \mathrm{m}^{2}$ IV bolus of 5 -FU, followed by $2400 \mathrm{mg} / \mathrm{m}^{2}$ as a $46-48 \mathrm{~h}$ continuous infusion. The cycle was repeated every 2 weeks for 6 months of perioperative therapy. (2) Day 1: oxaliplatin $130 \mathrm{mg} / \mathrm{m}^{2}$ IV. Days 1-14: capecitabine $1000 \mathrm{mg} / \mathrm{m}^{2}$ orally twice daily. The cycle was repeated every 3 weeks for 6 months of perioperative therapy. All patients were age 18 years or older and had provided signed informed consent and agreed to the use of their personal data for research. The primary inclusion criteria were as follows: (1) adenocarcinoma of colon or rectum diagnosed by histopathology, (2) stage II classified on the basis of the eighth edition of the AJCC/UICC TNM classification system, (3) complete patient information available, including baseline characteristics, follow-up and laboratory data. (4) all blood samples obtained within 1 week before the operation. Patients were excluded from this study on the basis of the following criteria: (1) neoadjuvant chemotherapy, (2) long-term use of anti-coagulant or anti-inflammatory medicine before surgery, (3) surgery in emergency circumstances, including obstruction and perforation. Follow-up was completed for all patients until December 2018. The median follow-up period was 49 months. The clinicopathological characteristics, including chemotherapy status, sex, age, tumor localization, tumor size, differentiation, $\mathrm{T}$ category, numbers of examined lymph nodes and status of vessel carcinoma embolus and cerebrovascular and cardiovascular diseases (CCVD), and 
laboratory data were collected from the electronic medical records. The neutrophil, platelet and lymphocyte counts were collected with routine blood tests. Albumin levels were determined with the hepatic function tests. PLR was defined as the absolute platelet count divided by the absolute lymphocyte count. NLR was defined as the absolute neutrophil count divided by the absolute lymphocyte count. LMR was defined as the absolute lymphocyte count divided by the absolute monocyte count. PNI was defined as $10 \times$ albumin level $(\mathrm{g} / \mathrm{dl})+0.005 \times$ lymphocyte count (per mm3) [27].

\section{Statistical analysis}

Subpopulation Treatment Effect Pattern Plot (STEPP) analysis was used to determine the optimal predictive inflammatory markers and cut-off values [28, 29]. The Mann-Whitney $U$ test and chi-square test were used to compare the differences in the inflammatory markers and other characteristics, respectively. Our survival analysis was based on overall survival (OS) and cancer-specific survival (CSS). The Kaplan-Meier method with the log-rank test was used to compare survival differences between the chemotherapy and non-chemotherapy groups. Univariate Cox proportional hazard regression analysis was used to calculate the hazard ratio (HR). Multivariate Cox proportional hazard regression analysis was used to assess the interactions between the clinicopathological characteristics and the effect of chemotherapy.

In a survival analysis, calculation of the survival probability at a specific time point is difficult. The restricted mean survival time (RMST) can be used as an alternative to summarize the profile [30,31]. The RMST was defined as the mean survival time by a certain time point with clinical meaning in the period of a study. It was equal to the area under the survival curve until the selected time point. The difference in RMST can be explained as the increase or decrease in survival time caused by a certain treatment. Consequently, the RMST was considered as an effective method to measure treatment effects. In our study, the RMST at 60 months, calculated by Kaplan-Meier survival analysis, was used.

In an observational study, researchers cannot control the treatment distribution, and large differences may exist in the covariates between the treated and nontreated groups. These differences are highly likely to cause a bias in treatment effect estimates. In our study, propensity score matching (PSM) [32-34] was performed to balance the covariates in the two groups and decrease this bias.

Statistical evaluation was performed using SPSS software version 25.0 (IBM Corporation, Armonk, NY, USA) and R software version 3.6.1 (St. Louis, Missouri, USA). All statistical tests were two-sided, and a $P$-value of less than 0.05 was considered to indicate a statistically significant difference.

\section{Results \\ Patient characteristics}

After the selection, a total of 708 patients with stage II $\mathrm{CRC}$ were included in the study. The clinicopathological characteristics of patients were summarized and compared with the chi-square test in Table 1 and MannWhitney U test in Table 2. A total of 447 (63.1\%) patients received chemotherapy and $261(36.9 \%)$ patients did not; $431(60.9 \%)$ patients were men and 277 (39.1\%) were women; $354(50.0 \%)$ patients had colon cancer and 354 $(50.0 \%)$ patients had rectal cancer. The median age of the patients was 63 years (range 23-88 years). According to the chi-square test and Mann-Whitney $U$ test, significant differences in age, differentiation, $\mathrm{T}$ category, cerebrovascular and cardiovascular diseases, LMR level and PNI level existed between chemotherapy and non-chemotherapy patients. Higher proportions of advanced age $(46.7 \%$ vs. $11.0 \%, p<0.001)$, poor differentiation $(9.6 \%$ vs. $6.0 \%, p=$ 0.038 ) and positive cardio-cerebrovascular comorbidities ( $16.9 \%$ vs. $10.7 \%, p=0.019)$ were observed in the nonchemotherapy patients, whereas the chemotherapy patients were more often diagnosed with the T4 category $(67.3 \%$ vs. $54.0 \%, \mathrm{p}<0.001)$.

\section{Optimal inflammatory marker}

STEPP was performed by plotting the level of the inflammatory markers NLR, PLR, LMR and PNI on the $\mathrm{x}$ axis and the cumulative mortality at 60 months, as measured by the Kaplan-Meier method, on the $y$-axis to compare the OS between the chemotherapy and nonchemotherapy patients in different subgroups divided by the levels of the inflammatory markers.

In the PLR-related analysis, when the PLR was $>130$, the cumulative mortality of the non-chemotherapy patients was significantly and continually higher than that of the chemotherapy patients, whereas the tendency was just in contrary when the PLR was $<130$ (Fig. 1A). Furthermore, no such tendency was found in the analyses of the other inflammatory markers (Fig. 1B, C and D). These results indicated that the PLR levels were closely associated with the survival benefits of chemotherapy. We further used a PLR level of 130 as the cut-off value to distinguish population in which chemotherapy was effective. We divided the patients into a high-PLR subgroup (PLR $\geq 130$ ) and low-PLR subgroup (PLR $<130$ ) and performed chisquare analysis to compare PLR levels between the chemotherapy and non-chemotherapy patients (Table 1).

\section{Overall survival analysis}

For all 708 patients with stage II CRC, chemotherapy patients had a longer OS than non-chemotherapy patients 
Table 1 Characteristics of patients

\begin{tabular}{|c|c|c|c|c|c|}
\hline \multicolumn{2}{|l|}{ Characteristics } & \multirow{2}{*}{$\begin{array}{l}\text { Total } \\
431(60.9 \%)\end{array}$} & \multirow{2}{*}{$\begin{array}{l}\text { Non-Chemotherapy } \\
156(59.8 \%)\end{array}$} & \multirow{2}{*}{$\begin{array}{l}\text { Chemotherapy } \\
275(61.5 \%)\end{array}$} & \multirow{2}{*}{$\frac{\boldsymbol{P}_{\text {value }} \mathbf{a}^{\mathbf{a}}}{0.645}$} \\
\hline Sex & Male & & & & \\
\hline & Female & 277 (39.1\%) & $105(40.2 \%)$ & $172(38.5 \%)$ & \\
\hline \multirow[t]{5}{*}{ Age (years) } & $\leq 55$ & 163 (23.0\%) & $32(12.3 \%)$ & 131 (29.3\%) & $<0.001$ \\
\hline & $56-60$ & $125(17.7 \%)$ & $23(8.8 \%)$ & $102(22.8 \%)$ & \\
\hline & $61-65$ & 146 (20.6\%) & 40 (15.3\%) & 106 (23.7\%) & \\
\hline & $66-70$ & $103(14.5 \%)$ & 44 (16.9\%) & 59 (13.2\%) & \\
\hline & $>70$ & $171(24.2 \%)$ & $122(46.7 \%)$ & 49 (11.0\%) & \\
\hline \multirow[t]{2}{*}{ Location } & Rectum & 354 (50.0\%) & $119(45.6 \%)$ & 235 (52.6\%) & 0.073 \\
\hline & Colon & 354 (50.0\%) & $142(54.4 \%)$ & $212(47.4 \%)$ & \\
\hline \multirow[t]{3}{*}{ Size (cm) } & $\leq 5.0$ & 395 (55.8\%) & $144(55.2 \%)$ & $251(56.2 \%)$ & 0.954 \\
\hline & $>5.0$ & 303 (42.8\%) & $113(43.3 \%)$ & $190(42.5 \%)$ & \\
\hline & Unknown & $10(1.4 \%)$ & $4(1.5 \%)$ & $6(1.3 \%)$ & \\
\hline \multirow[t]{3}{*}{ Differentiation } & Well-moderate & 654 (92.4\%) & 234 (89.7\%) & 420 (94.0\%) & 0.038 \\
\hline & Poor & $52(7.3 \%)$ & $25(9.6 \%)$ & $27(6.0 \%)$ & \\
\hline & Unknown & $2(0.3 \%)$ & $2(0.8 \%)$ & $0(0)$ & \\
\hline \multirow[t]{2}{*}{ T category } & 3 & 266 (37.6\%) & $120(46.0 \%)$ & 146 (32.7\%) & $<0.001$ \\
\hline & 4 & $442(62.4 \%)$ & $141(54.0 \%)$ & 301 (67.3\%) & \\
\hline \multirow[t]{3}{*}{$\mathrm{CEA}^{\mathrm{b}}(\mathrm{ng} / \mathrm{mL})$} & $<5$ & 388 (54.8\%) & $135(51.7 \%)$ & $253(56.6 \%)$ & 0.058 \\
\hline & $\geq 5$ & 237 (33.5\%) & $101(38.7 \%)$ & $136(30.4 \%)$ & \\
\hline & Unknown & $83(11.7 \%)$ & $25(9.6 \%)$ & $58(13.0 \%)$ & \\
\hline \multirow[t]{2}{*}{ Examined lymph nodes } & $<12$ & $186(26.3 \%)$ & 75 (28.7\%) & $111(24.8 \%)$ & 0.255 \\
\hline & $\geq 12$ & $522(73.7 \%)$ & $186(71.3 \%)$ & $336(75.2 \%)$ & \\
\hline \multirow[t]{2}{*}{ Vessel carcinoma embolus } & Negative & $683(96.5 \%)$ & $251(96.2 \%)$ & $432(96.6 \%)$ & 0.741 \\
\hline & Positive & $25(3.5 \%)$ & $10(3.8 \%)$ & $15(3.4 \%)$ & \\
\hline \multirow[t]{2}{*}{$C C V D^{c}$} & Negative & $616(87.0 \%)$ & $217(83.1 \%)$ & $399(89.3 \%)$ & 0.019 \\
\hline & Positive & $92(13.0 \%)$ & $44(16.9 \%)$ & $48(10.7 \%)$ & \\
\hline \multirow[t]{2}{*}{$P L R^{d}$} & $\leq 130$ & $371(52.4 \%)$ & $134(51.3 \%)$ & $237(53.0 \%)$ & 0.666 \\
\hline & $>130$ & $337(47.6 \%)$ & $127(48.7 \%)$ & $210(47.0 \%)$ & \\
\hline
\end{tabular}

a $P$ value of the Chi-square test

${ }^{b}$ CEA: carcinoembryonic antigen

c CCVD: cerebrovascular and cardiovascular diseases

d PLR: platelet to lymphocyte ratio

Table 2 Inflammatory markers of patients

\begin{tabular}{|c|c|c|c|c|c|c|c|}
\hline \multirow[t]{2}{*}{ Marker } & \multicolumn{2}{|l|}{ Total } & \multicolumn{2}{|c|}{ Non-chemotherapy } & \multicolumn{2}{|c|}{ Chemotherapy } & \multirow[t]{2}{*}{ P value $^{a}$} \\
\hline & Median & Interquartile Range & Median & Interquartile Range & Median & Interquartile Range & \\
\hline$\overline{P L R^{b}}$ & 127.60 & 71.64 & 128.49 & 74.81 & 125.84 & 69.56 & 0.562 \\
\hline$N L R^{c}$ & 1.94 & 1.28 & 2.02 & 1.27 & 1.88 & 1.30 & 0.080 \\
\hline $\operatorname{LMR}^{\mathrm{d}}$ & 4.21 & 2.58 & 3.91 & 2.53 & 4.28 & 2.56 & 0.008 \\
\hline $\mathrm{PNI}^{\mathrm{e}}$ & 50.28 & 7.33 & 48.90 & 8.05 & 50.75 & 6.75 & $<0.001$ \\
\hline
\end{tabular}

a $P$ value of Mann-Whitney $U$ test

${ }^{b}$ PLR: platelet to lymphocyte ratio

c NLR: neutrophil to lymphocyte ratio

d LMR: lymphocyte to monocyte ratio

e PNI: prognostic nutritional index 

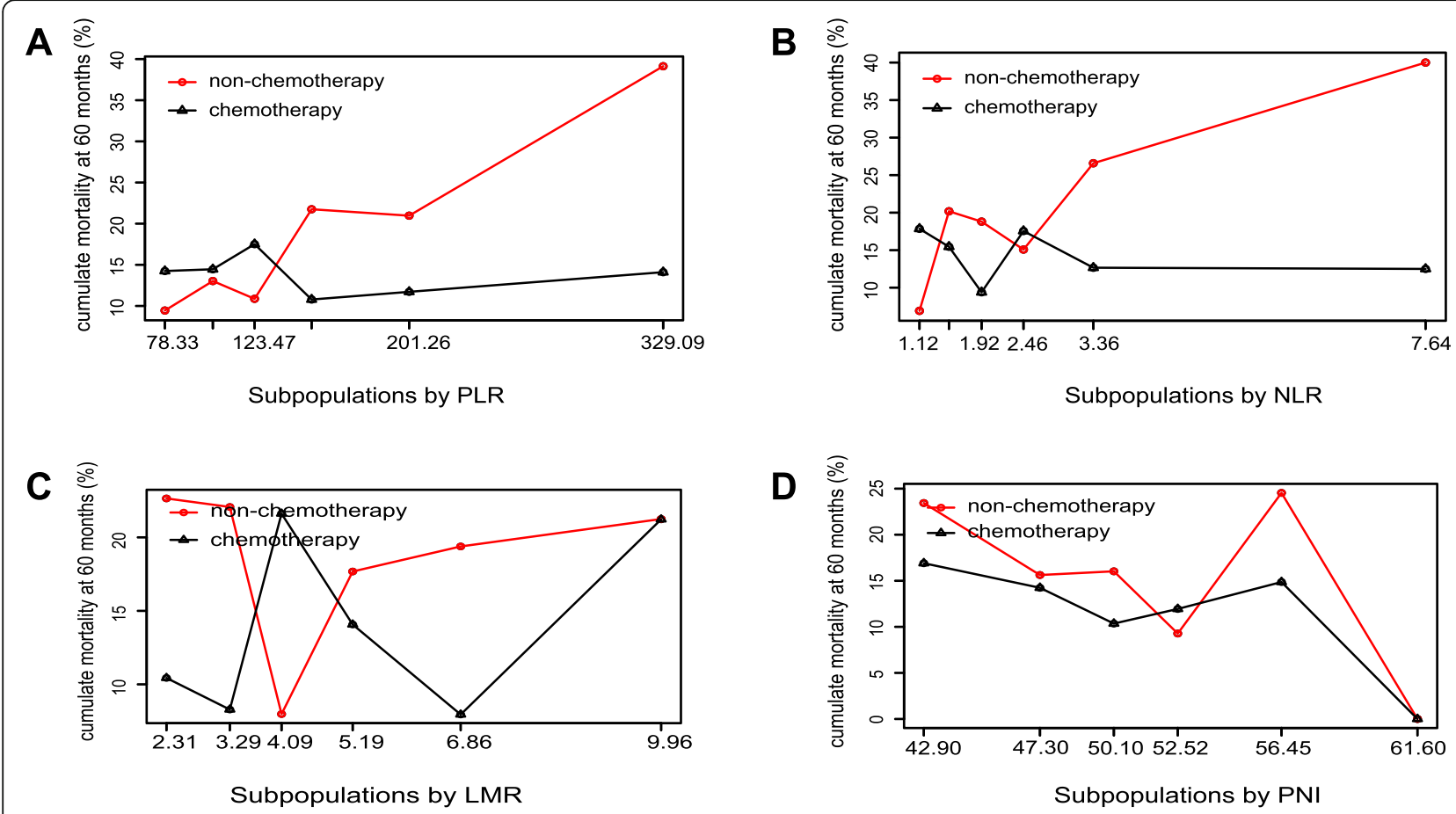

Fig. 1 STEPP analysis of the concerned inflammatory markers. (A) The result of PLR. (B) The result of NLR. (C) The result of LMR. (D) The result of PNI

(HR: 0.580, 95\%CI: 0.388-0.866, Fig. 2A). We also divided the patients into subgroups according to several characteristics including PLR level. The results of subgroup survival analysis indicated that the chemotherapy patients with the following characteristics had a longer OS than the non-chemotherapy patients: male (HR: 0.592, 95\%CI: $0.360-0.971$ ), rectal cancer (HR: 0.539, 95\% CI: $0.323-0.900)$, well or moderate differentiation (HR: $0.569,95 \%$ CI: 0.373-0.868), T4 category (HR: 0.501, 95\% CI: 0.318-0.791), number of examined lymph nodes $\geq 12$ (HR: $0.500,95 \%$ CI: $0.300-0.835$ ), and PLR level > 130 (HR: $0.371,95 \%$ CI: 0.212-0.649). The detailed results are shown in Table 3.

According to multivariate Cox survival analysis, PLR was the only characteristic significantly associated with the effects of chemotherapy (interaction $p=0.027$ ). In the low-PLR subgroup, the chemotherapy patients did not obtain OS benefits beyond those of the nonchemotherapy patients (HR: 0.983, 95\% CI: $0.528-1.829$, Fig. 2B). However, in the high-PLR subgroup, the chemotherapy patients had a significantly longer OS than the non-chemotherapy patients (HR: $0.371,95 \% \mathrm{CI}$ : 0.212-0.649, Fig. 2C). These results showed that PLR could distinguish the population in which chemotherapy is effective.

Considering that the high-risk factors and standard therapeutic approaches in stage II colon cancer and rectal cancer were not completely consistent, we also performed survival analyses in the colon cancer subgroup and the rectal cancer subgroup separately. The results of both subgroups were in accordance with the results for all patients with CRC, PLR was significantly associated with the effects of chemotherapy in both subgroups. For colon cancer: the chemotherapy patients did not have a longer OS than the nonchemotherapy patients (HR: 0.612, 95\%CI: 0.3211.168, Fig. 3A). In low-PLR subgroup, the chemotherapy patients did not have a longer OS (HR: 1.093, 95\%CI: 0.328-3.647, Fig. 3B). In high-PLR subgroup, the chemotherapy patients had a longer OS than nonchemotherapy patients (HR: 0.464, 95\% CI: 0.2111.024, Fig. 3C). For rectal cancer: the chemotherapy patients had a longer OS than the non-chemotherapy patients (HR: 0.539, 95\%CI: 0.323-0.900, Fig. 4A). In low-PLR subgroup, the chemotherapy patients did not have a longer OS (HR: 0.898, 95\%CI: 0.435-1.854, Fig. 4B). In high-PLR subgroup, the chemotherapy patients had a significantly longer OS (HR: 0.289 , 95\% CI: $0.131-0.638$, Fig. $4 C$ ). The detailed results of subgroup analysis are shown in Tables 4 and 5 .

\section{Overall survival analysis after PSM}

After PSM, 166 chemotherapy patients and 166 nonchemotherapy patients were paired. The characteristics of the matched patients are summarized and compared in Table 6. The differences in characteristics between 

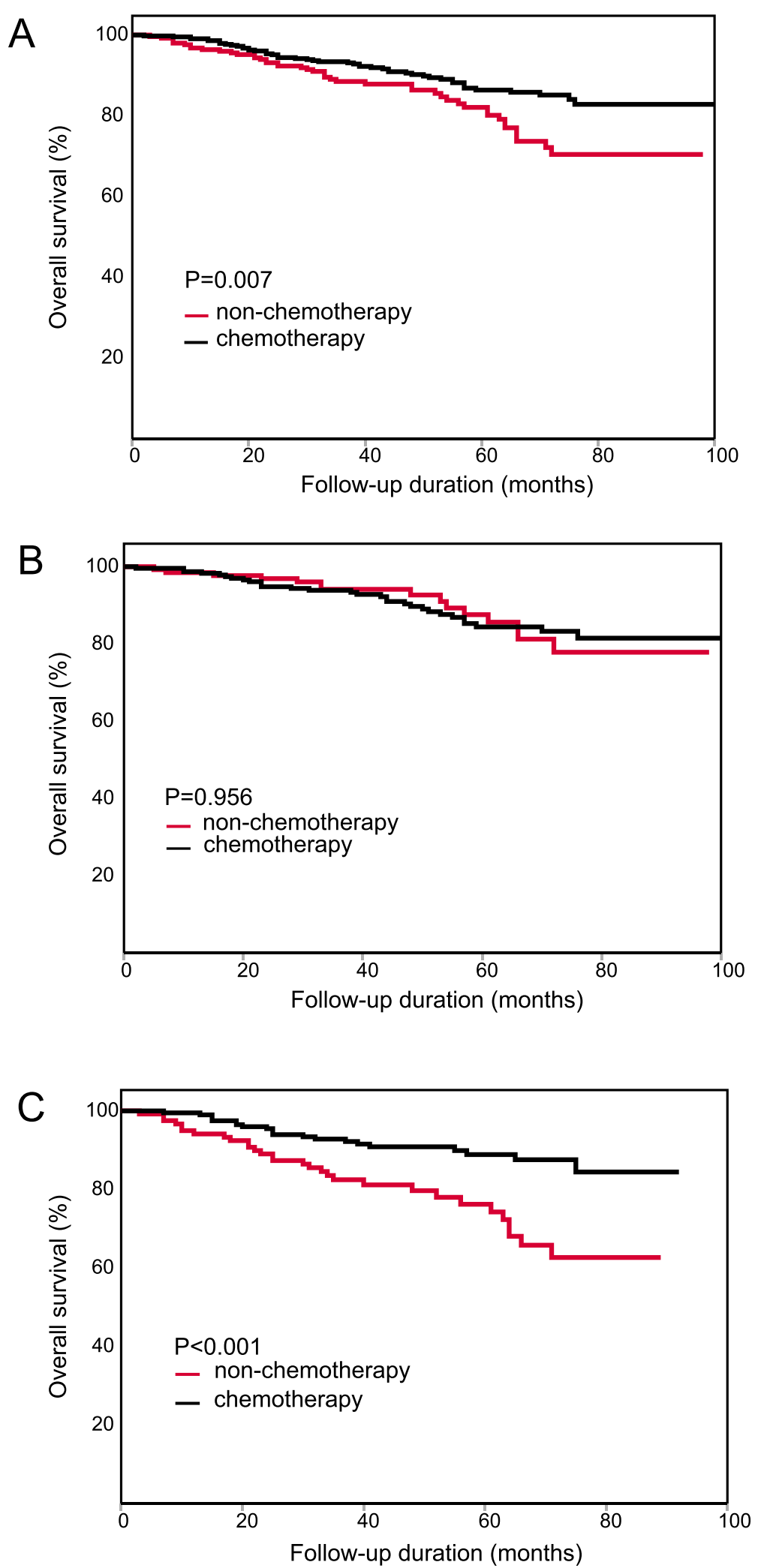

Fig. 2 Kaplan-Meier OS curve of patients with stage II CRC. (A) The result of all patients. (B) The result of the low-PLR subgroup. (C) The result of the high-PLR subgroup 
Table $\mathbf{3}$ OS analysis for all patients

\begin{tabular}{|c|c|c|c|c|c|c|}
\hline \multirow[t]{2}{*}{ Characteristics } & & \multicolumn{2}{|l|}{$\mathrm{RMST}^{\mathrm{b}}(95 \% \mathrm{Cl})$} & \multirow[t]{2}{*}{$\mathrm{HR}^{\mathrm{c}}(95 \% \mathrm{Cl})$} & \multirow[t]{2}{*}{$P$ value $^{a}$} & \multirow[t]{2}{*}{ Interaction $\mathrm{p}$} \\
\hline & & Non-chemotherapy & Chemotherapy & & & \\
\hline Total & - & $53.7(51.9-55.2)$ & $56.2(55.2-57.0)$ & $0.580(0.388-0.866)$ & 0.007 & - \\
\hline \multirow[t]{2}{*}{ Sex } & Male & $53.2(50.7-55.1)$ & $55.9(54.4-57.0)$ & $0.592(0.360-0.971)$ & 0.035 & 0.751 \\
\hline & Female & $54.5(51.7-56.4)$ & $56.8(54.8-58.0)$ & $0.560(0.282-1.112)$ & 0.093 & \\
\hline \multirow[t]{5}{*}{ Age (years) } & $\leq 55$ & $54.3(48.0-57.6)$ & $56.3(53.8-57.8)$ & $0.620(0.225-1.708)$ & 0.350 & 0.844 \\
\hline & $56-60$ & $55.4(47.4-58.5)$ & $56.8(54.4-58.2)$ & $0.725(0.199-2.634)$ & 0.623 & \\
\hline & $61-65$ & $53.3(46.5-56.9)$ & $55.7(52.9-57.5)$ & $0.636(0.240-1.683)$ & 0.357 & \\
\hline & $66-70$ & $53.2(48.1-56.4)$ & $57.3(53.6-58.8)$ & $0.355(0.118-1.063)$ & 0.053 & \\
\hline & $>70$ & $53.6(50.9-55.7)$ & $54.6(49.5-57.1)$ & $0.834(0.371-1.875)$ & 0.660 & \\
\hline \multirow[t]{2}{*}{ Location } & Rectum & $52.2(49.2-54.5)$ & $55.6(53.9-56.9)$ & $0.539(0.323-0.900)$ & 0.016 & 0.479 \\
\hline & Colon & $55.2(52.8-56.9)$ & $56.9(55.4-58.1)$ & $0.612(0.321-1.168)$ & 0.132 & \\
\hline \multirow[t]{2}{*}{ Size $(\mathrm{cm})$} & $\leq 5.0$ & $54.0(51.2-55.8)$ & $56.1(54.5-57.2)$ & $0.621(0.361-1.067)$ & 0.081 & 0.255 \\
\hline & $>5.0$ & $53.7(50.5-55.8)$ & $56.3(54.5-57.5)$ & $0.561(0.306-1.028)$ & 0.058 & \\
\hline \multirow[t]{2}{*}{ Differentiation } & Well-moderate & $53.9(52.0-55.4)$ & $56.3(55.2-57.2)$ & $0.569(0.373-0.868)$ & 0.008 & 0.396 \\
\hline & Poor & $52.0(43.2-56.6)$ & $54.7(46.8-57.8)$ & $0.662(0.177-2.471)$ & 0.534 & \\
\hline \multirow[t]{2}{*}{ T category } & 3 & $56.4(53.7-58.0)$ & $57.6(55.5-58.6)$ & $0.654(0.277-1.543)$ & 0.328 & 0.382 \\
\hline & 4 & $51.8(49.2-54.0)$ & $55.6(54.2-56.8)$ & $0.501(0.318-0.791)$ & 0.002 & \\
\hline \multirow[t]{2}{*}{$\mathrm{CEA}^{\mathrm{d}}(\mathrm{ng} / \mathrm{mL})$} & $<5$ & $54.6(51.9-56.4)$ & $56.7(55.3-57.8)$ & $0.585(0.323-1.060)$ & 0.073 & 0.482 \\
\hline & $\geq 5$ & $53.5(50.1-55.7)$ & $55.1(52.8-56.8)$ & $0.734(0.384-1.404)$ & 0.348 & \\
\hline \multirow[t]{2}{*}{ Examined lymph nodes } & $<12$ & $52.0(47.5-54.9)$ & $53.6(50.2-55.6)$ & $0.793(0.414-1.520)$ & 0.483 & 0.415 \\
\hline & $\geq 12$ & $54.5(52.3-56.0)$ & $57.1(55.9-57.9)$ & $0.500(0.300-0.835)$ & 0.007 & \\
\hline \multirow[t]{2}{*}{$P L R^{e}$} & $\leq 130$ & $56.0(53.6-57.6)$ & $56.0(54.3-57.2)$ & $0.983(0.528-1.829)$ & 0.956 & 0.027 \\
\hline & $>130$ & $51.3(47.8-53.7)$ & $56.5(54.8-57.7)$ & $0.371(0.212-0.649)$ & $<0.001$ & \\
\hline
\end{tabular}

a $P$ value of the log-rank test

b RMST: the restricted mean survival time

c HR: Hazard Ratio, chemotherapy patients vs. non-chemotherapy patients

d CEA: carcinoembryonic antigen

e PLR: platelet to lymphocyte ratio

chemotherapy and non-chemotherapy patients were acceptable.

In contrast to the results before PSM, the chemotherapy patients did not have a longer OS than the nonchemotherapy patients (HR: 0.584, 95\% CI: 0.333-1.025, Fig. 5A). The results of subgroup analysis showed that the chemotherapy patients with the following characteristics had a longer OS than the non-chemotherapy patients: male (HR: 0.487, 95\% CI: 0.240-0.991), T4 category (HR: $0.501,95 \%$ CI: 0.267-0.939), number of examined lymph nodes $\geq 12$ (HR: 0.404 , 95\% CI: $0.185-$ 0.882 ) and PLR level > 130 (HR: 0.272 , 95\% CI: $0.102-$ 0.726). The detailed results are shown in Table 7.

According to multivariate Cox survival analysis, PLR was still the only characteristic significantly associated with the effects of chemotherapy (interaction $p=0.038$ ). In the low-PLR subgroup, the chemotherapy patients did not obtain OS benefits beyond those of the nonchemotherapy patients. (HR: $1.080,95 \%$ CI: 0.495-2.355, Fig. 5B). In the high-PLR subgroup, the chemotherapy patients had a significantly longer OS than the nonchemotherapy patients (HR: 0.272, 95\% CI: 0.102-0.726, Fig. 5C). The results after PSM further confirmed that PLR could predict the effects of chemotherapy in patients with stage II CRC.

\section{Cancer-specific survival analysis}

For all patients, the chemotherapy patients did not obtain significant CSS benefits beyond those of the nonchemotherapy patients (HR: 0.673, 95\%CI: 0.412-1.101, Fig. 6A). According to subgroup analysis, chemotherapy patients with the following characteristics had a longer CSS than the non-chemotherapy patients: $66-70$ years old (HR: $0.172,95 \%$ CI: $0.036-0.834$ ) and PLR level > 130 (HR: $0.440,95 \%$ CI: 0.217-0.893). The detailed results are shown in Table 8.

The results of multivariate Cox survival analysis showed that PLR was not significantly associated with the effects of chemotherapy (interaction $p=0.116$ ). However, CSS benefits form chemotherapy between the 
A

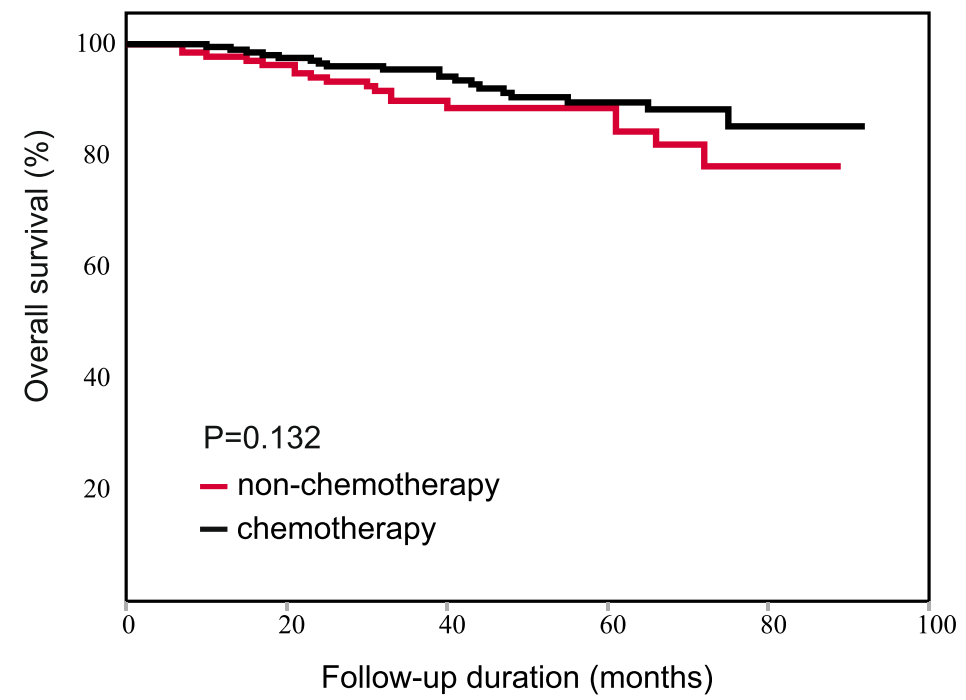

B

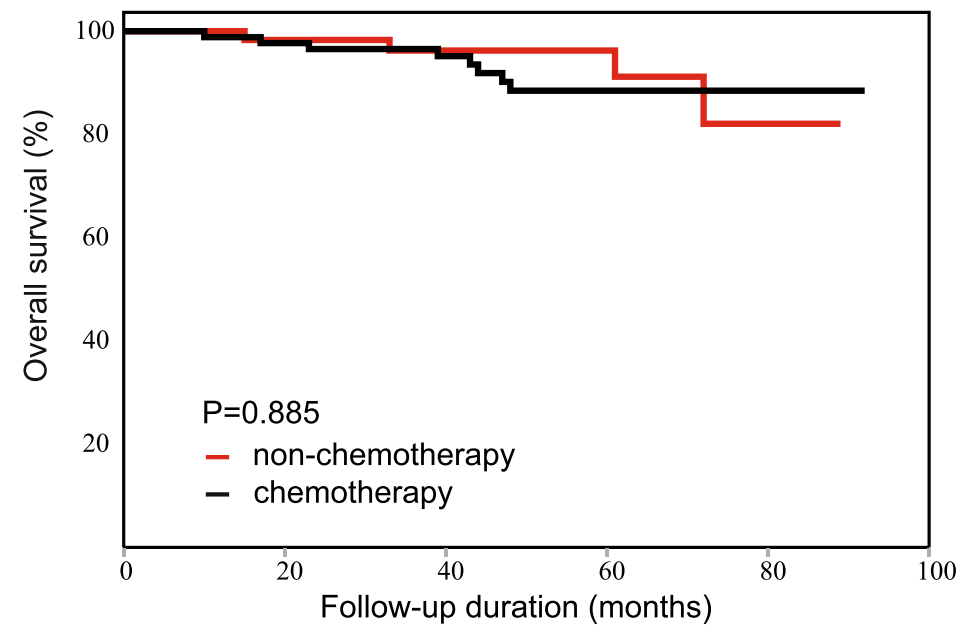

C

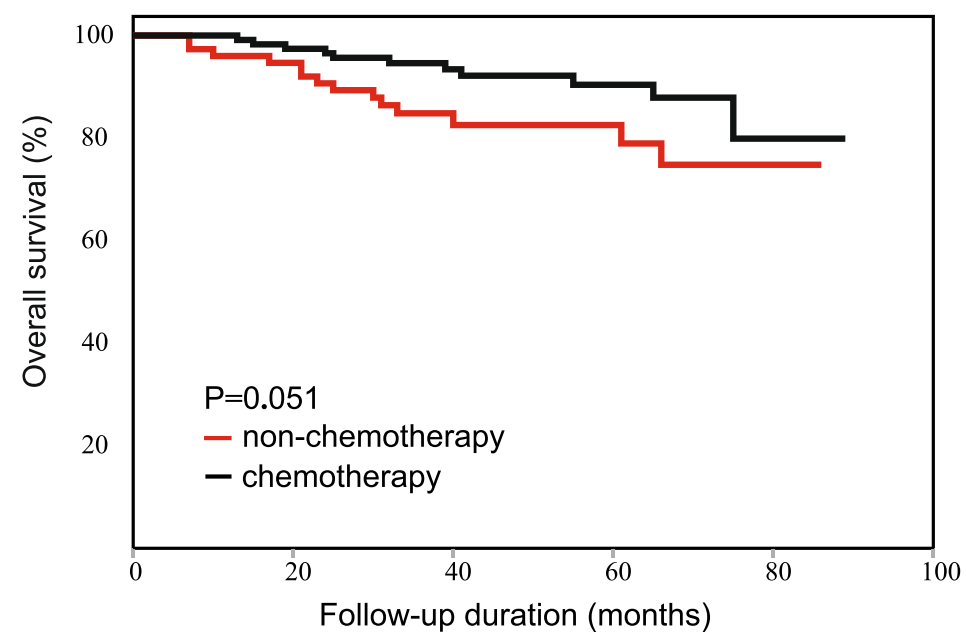

Fig. 3 Kaplan-Meier OS curve of patients with stage II colon cancer. (A) The result of all patients. (B) The result of the low-PLR subgroup. (C) The result of the high-PLR subgroup 

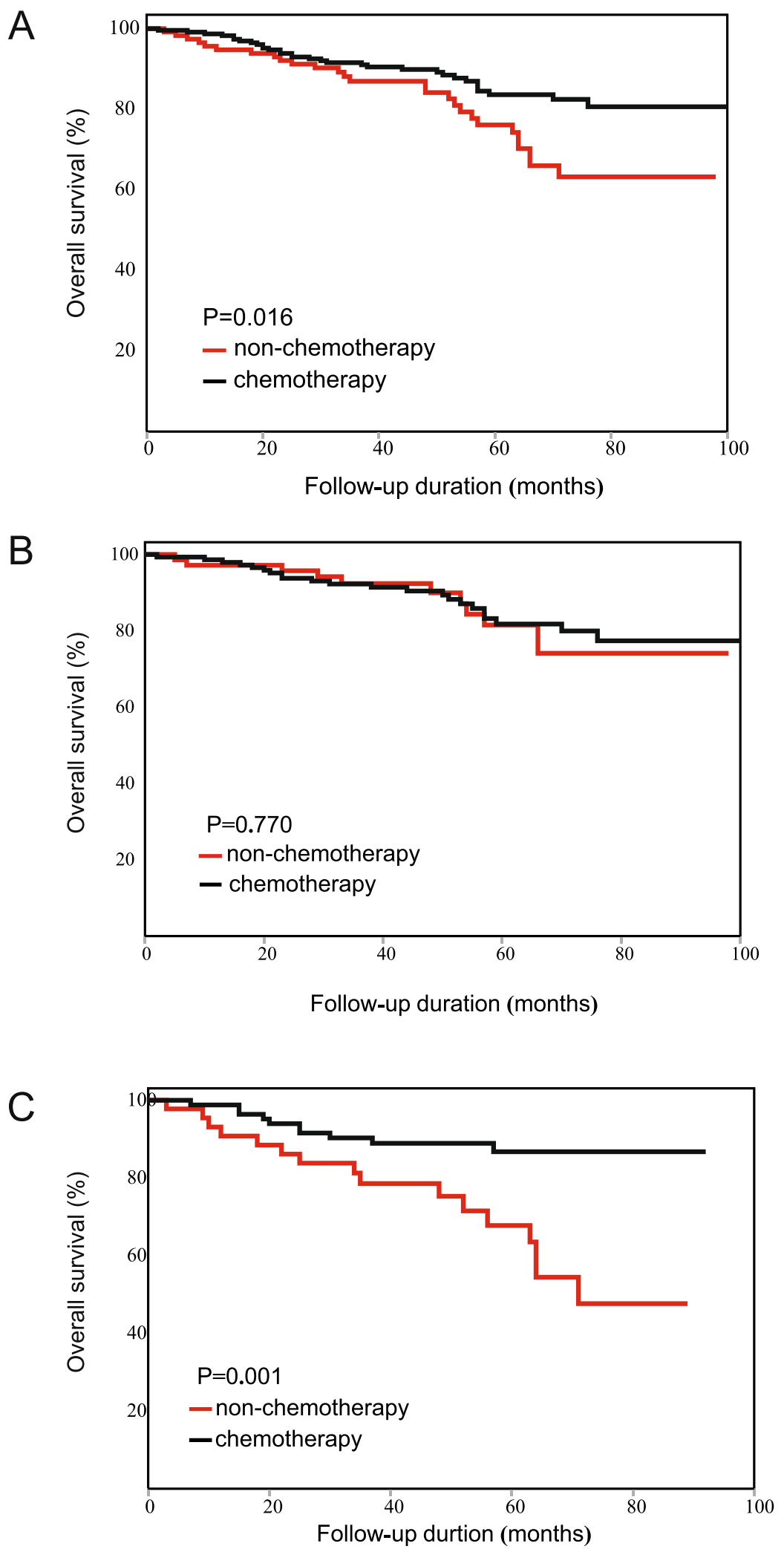

Fig. 4 Kaplan-Meier OS curve of patients with stage II rectal cancer. (A) The result of all patients. (B) The result of the low-PLR subgroup. (C) The result of the high-PLR subgroup 
Table 4 OS analysis for patients with colon cancer

\begin{tabular}{|c|c|c|c|c|c|c|}
\hline \multirow[t]{2}{*}{ Characteristics } & & \multicolumn{2}{|l|}{$\mathrm{RMST}^{\mathrm{b}}(95 \% \mathrm{Cl})$} & \multirow[t]{2}{*}{$\mathrm{HR}^{\mathrm{c}}(95 \% \mathrm{Cl})$} & \multirow[t]{2}{*}{$P$ value $^{a}$} & \multirow[t]{2}{*}{ Interaction $\mathrm{p}$} \\
\hline & & Non-chemotherapy & Chemotherapy & & & \\
\hline Total & - & $55.2(52.8-57.0)$ & $56.9(55.2-58.0)$ & $0.612(0.321-1.168)$ & 0.132 & - \\
\hline \multirow[t]{2}{*}{ Sex } & Male & $55.0(51.1-57.2)$ & $56.7(54.3-58.2)$ & $0.636(0.269-1.502)$ & 0.298 & 0.887 \\
\hline & Female & $55.4(51.1-57.7)$ & $57.2(54.5-58.6)$ & $0.599(0.225-1.599)$ & 0.301 & \\
\hline \multirow[t]{5}{*}{ Age (years) } & $\leq 55$ & $52.0(40.0-57.2)$ & $57.5(54.0-58.9)$ & $0.262(0.062-1.107)$ & 0.050 & 0.179 \\
\hline & $56-60$ & $56.0(38.7-59.5)$ & $57.0(52.2-58.9)$ & $0.849(0.095-7.617)$ & 0.884 & \\
\hline & $61-65$ & $55.4(43.1-58.8)$ & $55.7(51.1-57.8)$ & $0.882(0.176-4.421)$ & 0.879 & \\
\hline & $66-70$ & $52.9(45.9-56.5)$ & - & $0.015(0.001-10.71)$ & 0.014 & \\
\hline & $>70$ & $56.8(53.0-58.5)$ & $54.9(47.8-58.0)$ & $1.569(0.442-5.569)$ & 0.482 & \\
\hline \multirow[t]{2}{*}{ Size $(\mathrm{cm})$} & $\leq 5.0$ & $55.6(51.7-57.6)$ & $56.3(53.7-57.9)$ & $0.849(0.341-2.114)$ & 0.724 & 0.254 \\
\hline & $>5.0$ & $53.7(50.5-55.8)$ & $56.3(54.5-57.5)$ & $0.452(0.178-1.146)$ & 0.086 & \\
\hline \multirow[t]{2}{*}{ Differentiation } & Well-moderate & $53.9(52.0-55.4)$ & $56.3(55.2-57.2)$ & $0.621(0.310-1.246)$ & 0.175 & 0.990 \\
\hline & Poor & $52.0(43.2-56.6)$ & $54.7(46.8-57.8)$ & $0.594(0.099-3.561)$ & 0.564 & \\
\hline \multirow[t]{2}{*}{ T category } & 3 & $56.4(53.7-58.0)$ & $57.6(55.5-58.6)$ & $0.581(0.116-2.907)$ & 0.504 & 0.746 \\
\hline & 4 & $51.8(49.2-54.0)$ & $55.6(54.2-56.8)$ & $0.575(0.284-1.165)$ & 0.119 & \\
\hline \multirow[t]{2}{*}{$\mathrm{CEA}^{\mathrm{d}}(\mathrm{ng} / \mathrm{mL})$} & $<5$ & $54.6(51.9-56.4)$ & $56.7(55.3-57.8)$ & $0.606(0.219-1.675)$ & 0.329 & 0.522 \\
\hline & $\geq 5$ & $53.5(50.1-55.7)$ & $55.1(52.8-56.8)$ & $0.793(0.305-2.061)$ & 0.633 & \\
\hline \multirow[t]{2}{*}{ Examined lymph nodes } & $<12$ & $52.0(47.5-54.9)$ & $53.6(50.2-55.6)$ & $0.626(0.216-1.816)$ & 0.383 & 0.949 \\
\hline & $\geq 12$ & $54.5(52.3-56.0)$ & $57.1(55.9-57.9)$ & $0.670(0.293-1.534)$ & 0.340 & \\
\hline \multirow[t]{2}{*}{$P L R^{e}$} & $\leq 130$ & $56.0(53.6-57.6)$ & $56.0(54.3-57.2)$ & $1.093(0.328-3.647)$ & 0.885 & 0.276 \\
\hline & $>130$ & $51.3(47.8-53.7)$ & $56.5(54.8-57.7)$ & $0.464(0.211-1.024)$ & 0.051 & \\
\hline
\end{tabular}

${ }^{a} \mathrm{P}$ value of the log-rank test

b RMST: the restricted mean survival time

c HR: Hazard Ratio, chemotherapy patients vs. non-chemotherapy patients

${ }^{d}$ CEA: carcinoembryonic antigen

e PLR: platelet to lymphocyte ratio

low-PLR and high-PLR subgroup markedly differed. In the low-PLR subgroup, the chemotherapy patients did not have a longer CSS than the non-chemotherapy patients (HR: 1.016, 95\% CI: 0.494-2.087, Fig. 6B). In the high-PLR subgroup, the chemotherapy patients had a significantly longer CSS than the non-chemotherapy patients (HR: 0.440, 95\% CI: 0.217-0.893, Fig. 6C). The results indicated that PLR was still associated with the effects of chemotherapy measured by CSS.

According to survival analyses in the colon cancer subgroup and the rectal cancer subgroup, PLR was associated with the effects of chemotherapy in both subgroups. The results were in accordance with the results for all patients. For colon cancer: the chemotherapy patients did not have a longer CSS than the nonchemotherapy patients (HR: 0.775, 95\%CI: 0.355-1.691, Fig. 7A). In the low-PLR subgroup, the chemotherapy patients did not have a longer CSS (HR: 1.443, 95\%CI: 0.381-5.464, Fig. 7B). In the high-PLR subgroup, the chemotherapy patients had a tendency toward longer CSS than the non-chemotherapy patients, although the results were not statistically significant (HR: 0.506, 95\% CI: 0.183-1.397, Fig. 7C). For rectal cancer: the chemotherapy patients did not have a longer CSS than the non-chemotherapy patients (HR: 0.586, 95\%CI: 0.311-1.105, Fig. 8A). In the low-PLR subgroup, the chemotherapy patients did not have a longer CSS (HR: 0.833, 95\%CI: 0.352-1.967, Fig. 8B). In the high-PLR subgroup, the chemotherapy patients had a significantly longer CSS (HR: 0.360, 95\% CI: 0.134-0.969, Fig. 8C). The detailed results are shown in Tables 9 and 10.

\section{Cancer-specific survival analysis after PSM}

For the 332 matched patients, the chemotherapy patients did not have a longer CSS than the non-chemotherapy patients (HR: 0.684, 95\%CI: 0.332-1.409, Fig. 9A). According to the results of subgroup analysis, no survival difference between the chemotherapy and nonchemotherapy patients was found in any subgroup. The results indicated that no characteristics were associated with the effects of chemotherapy. The detailed results are shown in Table 11.

In multivariate Cox survival analysis, PLR was not significantly associated with the effects of chemotherapy (interaction $p=0.231$ ). In the low-PLR subgroup, the chemotherapy patients did not have a longer CSS than 
Table 5 OS analysis for patients with rectal cancer

\begin{tabular}{|c|c|c|c|c|c|c|}
\hline \multirow[t]{2}{*}{ Characteristics } & & \multicolumn{2}{|l|}{$\mathrm{RMST}^{\mathrm{b}}(95 \% \mathrm{Cl})$} & \multirow[t]{2}{*}{$\mathrm{HR}^{\mathrm{c}}(95 \% \mathrm{Cl})$} & \multirow[t]{2}{*}{$P$ value $^{a}$} & \multirow[t]{2}{*}{ Interaction $\mathrm{p}$} \\
\hline & & Non-chemotherapy & Chemotherapy & & & \\
\hline Total & - & $53.7(51.9-55.2)$ & $56.2(55.2-57.0)$ & $0.539(0.323-0.900)$ & 0.016 & - \\
\hline \multirow[t]{2}{*}{ Sex } & Male & $53.2(50.7-55.1)$ & $55.9(54.4-57.0)$ & $0.548(0.298-1.006)$ & 0.048 & 0.931 \\
\hline & Female & $54.5(51.7-56.4)$ & $56.8(54.8-58.0)$ & $0.534(0.205-1.391)$ & 0.192 & \\
\hline \multirow[t]{5}{*}{ Age (years) } & $\leq 55$ & $54.3(48.0-57.6)$ & $56.3(53.8-57.8)$ & $1.204(0.264-5.499)$ & 0.810 & 0.314 \\
\hline & $56-60$ & $55.4(47.4-58.5)$ & $56.8(54.4-58.2)$ & $0.698(0.141-3.459)$ & 0.658 & \\
\hline & $61-65$ & $53.3(46.5-56.9)$ & $55.7(52.9-57.5)$ & $0.490(0.142-1.694)$ & 0.250 & \\
\hline & $66-70$ & $53.2(48.1-56.4)$ & $57.3(53.6-58.8)$ & $0.605(0.143-2.551)$ & 0.489 & \\
\hline & $>70$ & $53.6(50.9-55.7)$ & $54.6(49.5-57.1)$ & $0.568(0.190-1.701)$ & 0.305 & \\
\hline \multirow[t]{2}{*}{ Size $(\mathrm{cm})$} & $\leq 5.0$ & $54.0(51.2-55.8)$ & $56.1(54.5-57.2)$ & $0.510(0.260-1.002)$ & 0.046 & 0.627 \\
\hline & $>5.0$ & $53.7(50.5-55.8)$ & $56.3(54.5-57.5)$ & $0.631(0.280-1.422)$ & 0.261 & \\
\hline \multirow[t]{2}{*}{ Differentiation } & Well-moderate & $53.9(52.0-55.4)$ & $56.3(55.2-57.2)$ & $0.519(0.305-0.883)$ & 0.014 & 0.309 \\
\hline & Poor & $52.0(43.2-56.6)$ & $54.7(46.8-57.8)$ & $0.727(0.102-5.208)$ & 0.750 & \\
\hline \multirow[t]{2}{*}{ T category } & 3 & $56.4(53.7-58.0)$ & $57.6(55.5-58.6)$ & $0.698(0.253-1.925)$ & 0.484 & 0.350 \\
\hline & 4 & $51.8(49.2-54.0)$ & $55.6(54.2-56.8)$ & $0.431(0.237-0.784)$ & 0.004 & \\
\hline \multirow[t]{2}{*}{$\mathrm{CEA}^{\mathrm{d}}(\mathrm{ng} / \mathrm{mL})$} & $<5$ & $54.6(51.9-56.4)$ & $56.7(55.3-57.8)$ & $0.568(0.273-1.181)$ & 0.124 & 0.523 \\
\hline & $\geq 5$ & $53.5(50.1-55.7)$ & $55.1(52.8-56.8)$ & $0.660(0.273-1.598)$ & 0.354 & \\
\hline \multirow[t]{2}{*}{ Examined lymph nodes } & $<12$ & $52.0(47.5-54.9)$ & $53.6(50.2-55.6)$ & $0.885(0.375-2.091)$ & 0.780 & 0.169 \\
\hline & $\geq 12$ & $54.5(52.3-56.0)$ & $57.1(55.9-57.9)$ & $0.401(0.208-0.771)$ & 0.005 & \\
\hline \multirow[t]{2}{*}{$P L R^{e}$} & $\leq 130$ & $56.0(53.6-57.6)$ & $56.0(54.3-57.2)$ & $0.898(0.435-1.854)$ & 0.770 & 0.033 \\
\hline & $>130$ & $51.3(47.8-53.7)$ & $56.5(54.8-57.7)$ & $0.289(0.131-0.638)$ & 0.001 & \\
\hline
\end{tabular}

${ }^{a} \mathrm{P}$ value of the log-rank test

${ }^{b}$ RMST: the restricted mean survival time

c HR: Hazard Ratio, chemotherapy patients vs. non-chemotherapy patients

${ }^{d}$ CEA: carcinoembryonic antigen

e PLR: platelet to lymphocyte ratio

the non-chemotherapy patients (HR: 0.963, 95\%CI: 0.379-2.449, Fig. 9B). In the high-PLR subgroup, the chemotherapy patients had a tendency toward longer CSS than the non-chemotherapy patients, although the results were not statistically significant (HR: 0.372, 95\% CI: 0.100-1.374, Fig. 9C).

\section{Discussion}

Guidelines suggest patients with high-risk stage II CRC should receive adjuvant chemotherapy [8-12]. The NCCN guidelines define patients meeting the following criteria as the high-risk population: T4 depth of invasion, peritumoral lymphatic/venous invasion, histologic grade of 3 or greater, R1-R2 margin status, bowel obstruction or perforation or fewer than 12 nodes retrieved. Furthermore, patients are also defined as highrisk by the ASCO guidelines if they have elevated carcinoembryonic antigen (CEA) $(\mathrm{CEA}>5 \mathrm{ng} / \mathrm{ml})$. Although these high-risk characteristics, as determined by the OS benefits, can distinguish the population with poorer prognosis from all patients with stage II CRC, they cannot predict additional survival benefits from chemotherapy in this population. Given the lack of statistically significance differences in survival between the chemotherapy and non-chemotherapy population and the side effects that chemotherapy may cause $[35,36]$, chemotherapy may do more harm than good for certain patients with stage II CRC. Given this background, novel biomarkers are needed to distinguish the population in which chemotherapy will be effective among patients with stage II CRC.

Substantial evidence indicates that the progression of a tumor depends on not only the tumor itself, but also the inflammatory response of the host [37]. The inflammatory response has been demonstrated to lead to impaired immune function and an anti-tumor immune response of the host. This response has been widely accepted as an important stage-independent indicator, particularly in renal, gastro-esophageal and colorectal cancers. In fact, inflammatory cells, such as neutrophils, lymphocytes, platelets and monocytes, have been used in prognostic prediction for CRC patients $[17,19,21,38]$. Furthermore, some studies have demonstrated an interaction between inflammation and the response or resistance of chemotherapy $[22-26,39]$. The results of these studies indicated 
Table 6 Characteristics of patients after PSM

\begin{tabular}{|c|c|c|c|c|c|}
\hline Characteristics & & Total & Non-chemotherapy & Chemotherapy & P value $^{\mathrm{a}}$ \\
\hline \multirow[t]{2}{*}{ Sex } & Male & 199 (59.9\%) & 97 (58.4\%) & $102(61.4 \%)$ & 0.575 \\
\hline & Female & $133(40.1 \%)$ & 69 (41.6\%) & $64(38.6 \%)$ & \\
\hline \multirow[t]{5}{*}{ Age (years) } & $\leq 55$ & $58(17.4 \%)$ & 30 (18.1\%) & $28(16.9 \%)$ & 0.879 \\
\hline & $56-60$ & $42(12.7 \%)$ & 20 (12.0\%) & $22(13.2 \%)$ & \\
\hline & $61-65$ & 65 (19.6\%) & $32(19.3 \%)$ & 33 (19.9\%) & \\
\hline & $66-70$ & 74 (22.3\%) & 34 (20.5\%) & 40 (24.1\%) & \\
\hline & $>70$ & 93 (28.0\%) & 50 (30.1\%) & $43(25.9 \%)$ & \\
\hline \multirow[t]{2}{*}{ Location } & Rectum & $171(51.5 \%)$ & 88 (53.0\%) & 83 (50.0\%) & 0.583 \\
\hline & Colon & 161 (48.5\%) & 78 (47.0\%) & $83(50.0 \%)$ & \\
\hline \multirow[t]{3}{*}{ Size (cm) } & $\leq 5.0$ & $183(55.1 \%)$ & 92 (55.4\%) & 91 (54.8\%) & 0.833 \\
\hline & $>5.0$ & $143(44.0 \%)$ & $72(43.4 \%)$ & $74(44.6 \%)$ & \\
\hline & Unknown & $3(0.9 \%)$ & $2(1.2 \%)$ & $1(0.6 \%)$ & \\
\hline \multirow[t]{2}{*}{ Differentiation } & Well-moderate & 309 (93.1\%) & 154 (92.8\%) & 155 (93.4\%) & 0.829 \\
\hline & Poor & $23(6.9 \%)$ & $12(7.2 \%)$ & $11(6.6 \%)$ & \\
\hline \multirow[t]{2}{*}{ T category } & 3 & 127 (38.3\%) & $62(37.3 \%)$ & $65(39.2 \%)$ & 0.735 \\
\hline & 4 & 205 (61.7\%) & $104(62.7 \%)$ & 101 (60.8\%) & \\
\hline \multirow[t]{3}{*}{$\mathrm{CEA}^{\mathrm{b}}(\mathrm{ng} / \mathrm{mL})$} & $<5$ & 175 (52.7\%) & $88(53.0 \%)$ & $87(52.4 \%)$ & 0.968 \\
\hline & $\geq 5$ & 118 (35.5\%) & 58 (34.9\%) & $60(36.1 \%)$ & \\
\hline & Unknown & 39 (11.8\%) & 20 (12.1\%) & $19(11.5 \%)$ & \\
\hline \multirow[t]{2}{*}{ Examined lymph nodes } & $<12$ & $84(25.3 \%)$ & $41(24.7 \%)$ & $43(25.9 \%)$ & 0.801 \\
\hline & $\geq 12$ & $248(74.7 \%)$ & $125(75.3 \%)$ & $123(74.1 \%)$ & \\
\hline \multirow[t]{2}{*}{ Vessel carcinoma embolus } & Negative & $320(96.4 \%)$ & $160(96.4 \%)$ & 160 (96.4\%) & 1.000 \\
\hline & Positive & $12(3.6 \%)$ & $6(3.6 \%)$ & $6(3.6 \%)$ & \\
\hline \multirow[t]{2}{*}{$\mathrm{CCVD}^{\mathrm{C}}$} & Negative & $287(86.4 \%)$ & $147(88.6 \%)$ & $140(84.3 \%)$ & 0.262 \\
\hline & Positive & $45(13.6 \%)$ & 19 (11.4\%) & $26(15.7 \%)$ & \\
\hline \multirow[t]{2}{*}{$P L R^{d}$} & $\leq 130$ & $176(53.0 \%)$ & $85(51.2 \%)$ & $91(54.8 \%)$ & 0.509 \\
\hline & $>130$ & $156(47.0 \%)$ & 81 (48.8\%) & 75 (45.2\%) & \\
\hline
\end{tabular}

a value of the Chi-square test

${ }^{b}$ CEA: carcinoembryonic antigen

c CCVD: cerebrovascular and cardiovascular diseases

d PLR: platelet to lymphocyte ratio

that predicting the effects of chemotherapy with inflammatory biomarkers was feasible.

Many studies have been performed to explore the clinical application of PLR, an important inflammatory marker. Several studies have found that elevated PLR was an indicator of poor prognosis in patients with CRC [19, 40]. However, the clinical application of PLR in patients with stage II CRC remains controversial. Ozawa et al. have indicated that PLR could be used as a prognostic marker in patients with stage II CRC who have undergone curative surgery but not adjuvant chemotherapy [41]. Some studies have shown that elevated PLR was significantly associated with poor survival in both stage II and III CRC $[42,43]$, whereas You et al. have reported that PLR was associated with survival outcomes in stage III CRC but not in stage II CRC [44]. Notably, most studies on PLR's clinical application have focused on prognosis but not the effects of chemotherapy. Our study aimed at providing chemotherapy guidance is substantially different from these studies.

To our knowledge, our study is the first to predict the effect of chemotherapy in patients with stage II CRC. We found that PLR was the only characteristic associated with the effects of chemotherapy among all characteristics examined, including other inflammatory markers. Patients with elevated PLR obtained a significant survival benefit from chemotherapy, whereas patients with low PLR did not. PLR was able to predict the effects of chemotherapy and to distinguish the population in which chemotherapy is effective among patients with stage II CRC. However, some of our results differed from the guidelines and previous studies. According to the guidelines, patients with 

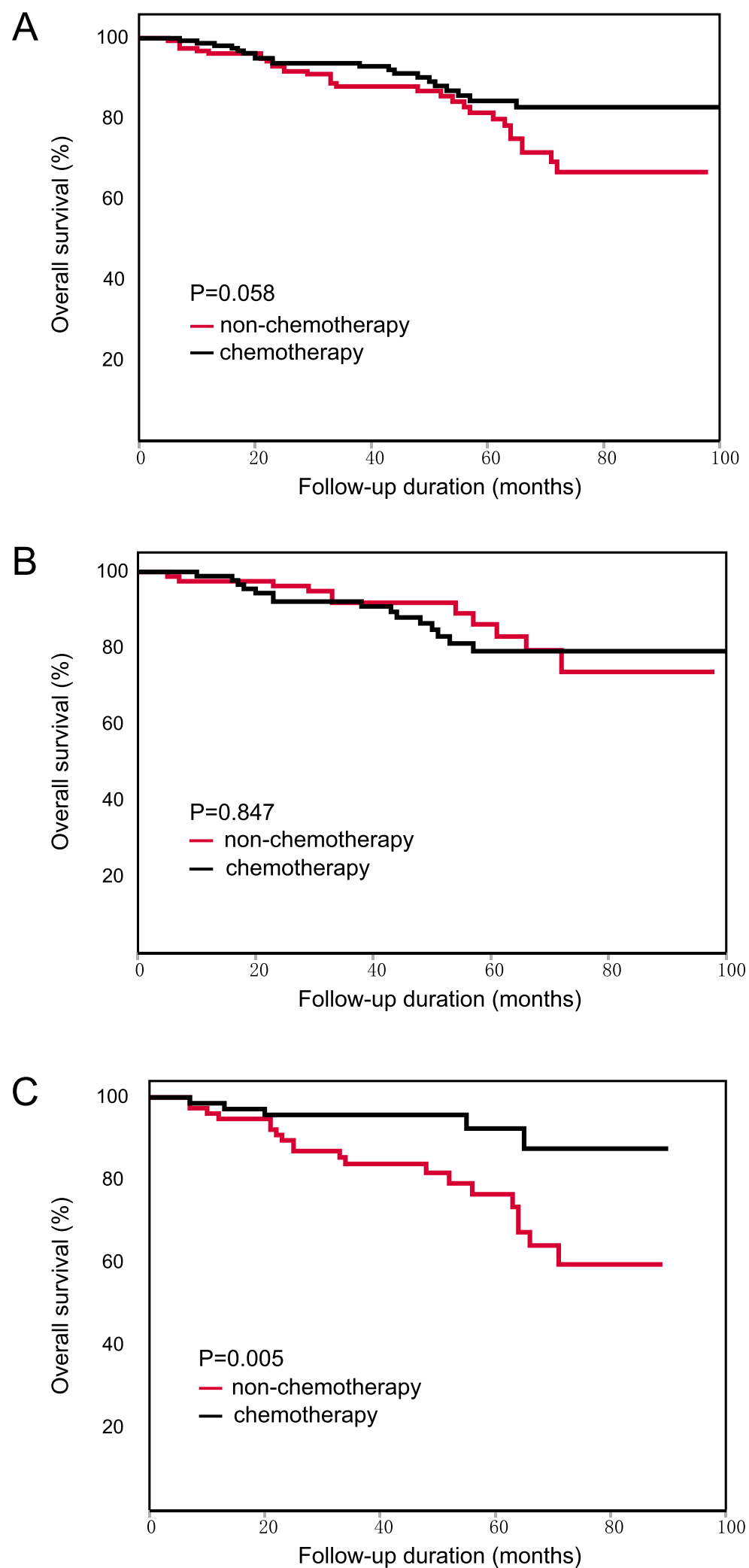

Fig. 5 Kaplan-Meier OS curve of patients with stage II CRC after PSM. (A) The result of all patients. (B) The result of the low-PLR subgroup. (C) The result of the high-PLR subgroup 
Table 7 OS analysis for patients after PSM

\begin{tabular}{|c|c|c|c|c|c|c|}
\hline \multirow[t]{2}{*}{ Characteristics } & & \multicolumn{2}{|l|}{ RMST $^{\mathrm{b}}(95 \% \mathrm{Cl})$} & \multirow[t]{2}{*}{$\mathrm{HR}^{\mathrm{c}}(95 \% \mathrm{Cl})$} & \multirow[t]{2}{*}{$P$ value $^{a}$} & \multirow[t]{2}{*}{ Interaction $\mathrm{p}$} \\
\hline & & Non- Chemotherapy & Chemotherapy & & & \\
\hline Total & - & $53.3(50.9-55.2)$ & $56.0(54.0-57.4)$ & $0.584(0.333-1.025)$ & 0.058 & - \\
\hline \multirow[t]{2}{*}{ Sex } & Male & $52.0(48.1-54.6)$ & $55.9(53.2-57.6)$ & $0.487(0.240-0.991)$ & 0.042 & 0.157 \\
\hline & Female & $55.0(50.7-57.2)$ & $56.1(52.8-58.0)$ & $0.787(0.310-2.003)$ & 0.615 & \\
\hline \multirow[t]{5}{*}{ Age (years) } & $\leq 55$ & $53.8(46.6-57.2)$ & $56.6(50.7-59.0)$ & $0.536(0.128-2.251)$ & 0.386 & 0.574 \\
\hline & $56-60$ & $54.6(45.6-58.2)$ & $57.1(48.8-59.2)$ & $0.584(0.097-3.499)$ & 0.551 & \\
\hline & $61-65$ & $53.2(45.7-57.0)$ & $55.6(49.8-58.3)$ & $0.641(0.171-2.403)$ & 0.505 & \\
\hline & $66-70$ & $54.2(47.2-57.3)$ & $57.5(52.6-59.1)$ & $0.392(0.098-1.576)$ & 0.170 & \\
\hline & $>70$ & $52.0(46.9-55.2)$ & $53.9(49.1-56.9)$ & $0.748(0.305-1.830)$ & 0.522 & \\
\hline \multirow[t]{2}{*}{ Location } & Rectum & $52.4(48.6-55.0)$ & $54.6(51.2-56.8)$ & $0.725(0.366-1.435)$ & 0.353 & 0.283 \\
\hline & Colon & $54.5(50.6-56.9)$ & $57.5(54.9-58.9)$ & $0.428(0.158-1.163)$ & 0.086 & \\
\hline \multirow[t]{2}{*}{ Size $(\mathrm{cm})$} & $\leq 5.0$ & $54.3(50.8-56.6)$ & $56.7(54.0-58.1)$ & $0.548(0.236-1.269)$ & 0.153 & 0.165 \\
\hline & $>5.0$ & $52.6(48.6-55.4)$ & $55.1(51.8-57.3)$ & $0.672(0.312-1.449)$ & 0.307 & \\
\hline \multirow[t]{2}{*}{ Differentiation } & Well-moderate & $53.5(50.8-55.4)$ & $56.1(54.0-57.5)$ & $0.570(0.315-1.031)$ & 0.059 & 0.702 \\
\hline & Poor & $50.5(36.8-56.9)$ & $53.8(39.9-58.2)$ & $0.711(0.117-4.339)$ & 0.708 & \\
\hline \multirow[t]{2}{*}{ T category } & 3 & $58.1(54.7-59.3)$ & $57.3(54.2-58.9)$ & $1.439(0.342-6.045)$ & 0.618 & 0.072 \\
\hline & 4 & $50.9(47.1-53.4)$ & $55.2(52.1-57.0)$ & $0.501(0.267-0.939)$ & 0.027 & \\
\hline \multirow[t]{2}{*}{$\mathrm{CEA}^{\mathrm{d}}(\mathrm{ng} / \mathrm{mL})$} & $<5$ & $55.2(51.8-57.1)$ & $57.3(54.4-58.7)$ & $0.557(0.219-1.414)$ & 0.211 & 0.790 \\
\hline & $\geq 5$ & $52.4(46.8-55.7)$ & $55.0(51.0-57.4)$ & $0.641(0.265-1.552)$ & 0.320 & \\
\hline \multirow[t]{2}{*}{ Examined lymph nodes } & $<12$ & $50.7(44.5-54.8)$ & $51.7(46.5-55.1)$ & $0.898(0.381-2.118)$ & 0.806 & 0.322 \\
\hline & $\geq 12$ & $54.1(51.4-56.0)$ & $57.5(55.5-58.7)$ & $0.404(0.185-0.882)$ & 0.018 & \\
\hline \multirow[t]{2}{*}{$P L R^{e}$} & $\leq 130$ & $55.3(51.8-57.4)$ & $54.9(52.0-56.8)$ & $1.080(0.495-2.355)$ & 0.847 & 0.038 \\
\hline & $>130$ & $51.3(47.2-54.2)$ & $57.6(54.2-59.0)$ & $0.272(0.102-0.726)$ & 0.005 & \\
\hline
\end{tabular}

a $P$ value of the log-rank test

b RMST: the restricted mean survival time

' HR: Hazard Ratio, chemotherapy patients vs. non-chemotherapy patients

d CEA: carcinoembryonic antigen

e PLR: platelet to lymphocyte ratio

poor pathological differentiation or inadequate nodal resection are recommended to receive chemotherapy, while this population did not obtain a survival benefit from chemotherapy in our study. The possible reasons for the contradictory result may be as follows: First, selection bias may have resulted from the retrospective and singlecenter nature of our study. Second, the sample sizes of the subgroups may have been insufficient. Third, chemotherapy is not significantly effective in patients with poor pathological differentiation and inadequate nodal resection, although this population is recommended to receive chemotherapy. Furthermore, PLR was not significantly associated with the effects of chemotherapy in CSS analysis. The possible reasons may be as follows: First, the relatively small number of events, owing the insufficient sample size and good prognosis in patients in our study. Second, the intervention of other factors intricated in survival. For example, among all patients with elevated PLR, cardiovascular complications may be more common in the chemotherapy group than non-chemotherapy group.
There are also some other limitations in our study. First, the inability to analyze the role of bowel obstruction and perforation. Inflammatory-related indicators, such as neutrophil, platelet, lymphocyte counts and albumin levels, would largely deviate from the general level in a setting of bowel obstruction or perforation, therefore, patients with bowel obstruction or perforation were excluded from our analysis. Secondly, because of the relatively smaller number of patients who received single-agent therapy, we compared only the survival benefits between chemotherapy and non-chemotherapy patients, further comparison among different chemotherapy regimens was not performed. Third, as an important factor of chemotherapy decision in stage II CRC, we did not include microsatellite instability (MSI) in our study due to the lack of information. Last, PSM was performed to balance the covariates between the chemotherapy and nonchemotherapy group and to minimize the bias. However, as a retrospective study, the bias could not be completely eliminated. We will focus on these 

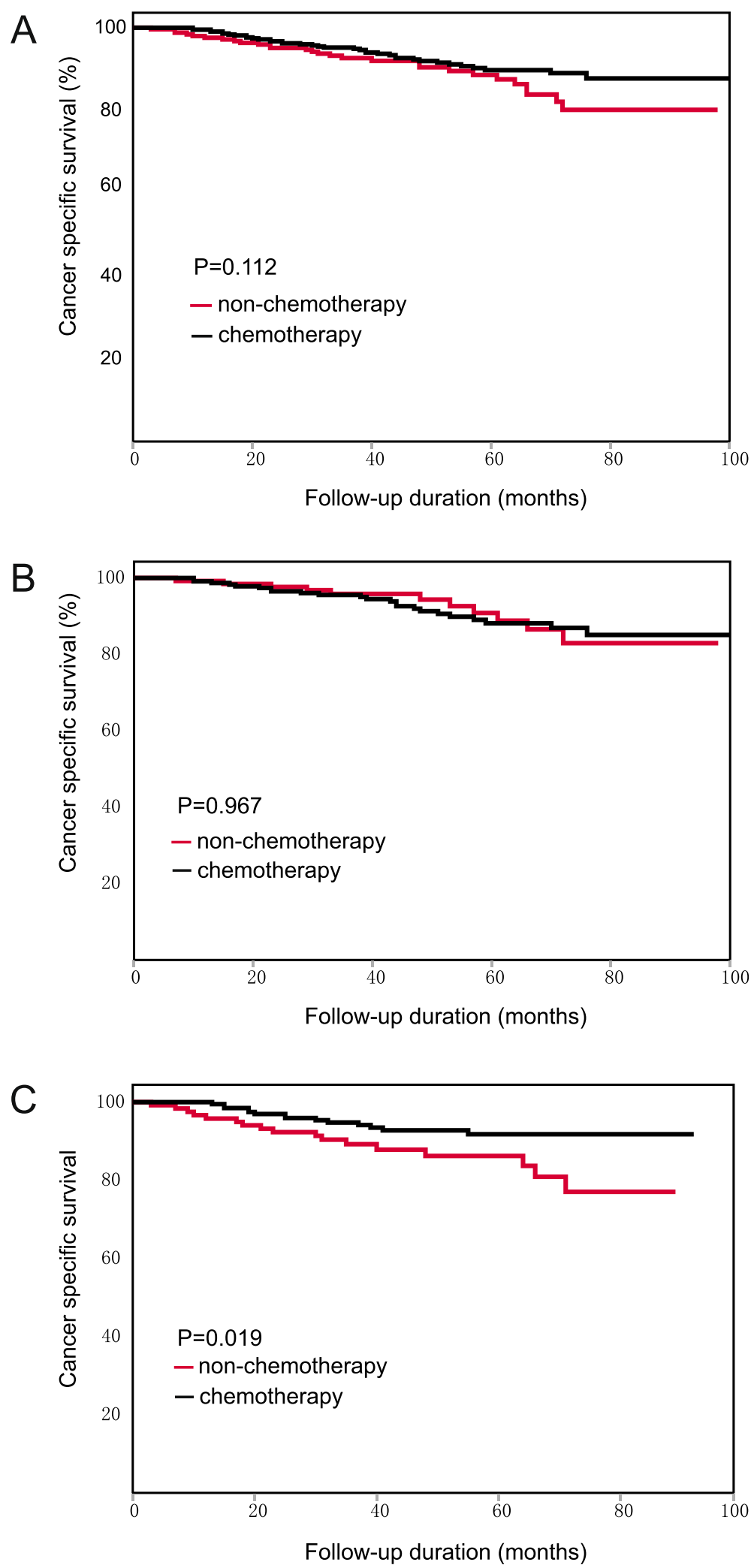

Fig. 6 Kaplan-Meier CSS curve of patients with stage II CRC. (A) The result of all patients. (B) The result of the low-PLR subgroup. (C) The result of the high-PLR subgroup 
Table 8 CSS analysis for all patients

\begin{tabular}{|c|c|c|c|c|c|c|}
\hline \multirow[t]{2}{*}{ Characteristics } & & \multicolumn{2}{|l|}{$\mathrm{RMST}^{\mathrm{b}}(95 \% \mathrm{Cl})$} & \multirow[t]{2}{*}{$\mathrm{HR}^{\mathrm{c}}(95 \% \mathrm{Cl})$} & \multirow[t]{2}{*}{ P value ${ }^{a}$} & \multirow[t]{2}{*}{ Interaction $\mathrm{p}$} \\
\hline & & Non-chemotherapy & Chemotherapy & & & \\
\hline Total & - & $53.8(51.7-55.3)$ & $56.2(50.1-57.1)$ & $0.673(0.412-1.101)$ & 0.112 & - \\
\hline \multirow[t]{2}{*}{ Sex } & Male & $53.2(50.7-55.3)$ & $55.9(54.4-57.1)$ & $0.598(0.330-1.084)$ & 0.086 & 0.393 \\
\hline & Female & $54.5(51.3-56.5)$ & $56.8(55.0-58.0)$ & $0.882(0.365-2.134)$ & 0.781 & \\
\hline \multirow[t]{5}{*}{ Age (years) } & $\leq 55$ & $54.3(47.9-57.4)$ & $56.3(54.2-57.7)$ & $0.669(0.218-2.053)$ & 0.479 & 0.986 \\
\hline & $56-60$ & $55.4(47.4-58.5)$ & $56.8(54.2-58.3)$ & $0.656(0.132-3.250)$ & 0.602 & \\
\hline & $61-65$ & $53.3(46.5-57.0)$ & $55.7(52.8-57.4)$ & $0.720(0.224-2.314)$ & 0.519 & \\
\hline & $66-70$ & $53.2(48.2-56.3)$ & $57.3(53.7-58.8)$ & $0.172(0.036-0.834)$ & 0.013 & \\
\hline & $>70$ & $53.6(50.6-55.8)$ & $54.6(50.0-57.2)$ & $1.240(0.458-3.356)$ & 0.671 & \\
\hline \multirow[t]{2}{*}{ Location } & Rectum & $52.2(49.2-54.5)$ & $55.6(53.8-56.9)$ & $0.586(0.311-1.105)$ & 0.094 & 0.445 \\
\hline & Colon & $55.2(52.6-56.9)$ & $56.9(55.4-58.0)$ & $0.775(0.355-1.691)$ & 0.521 & \\
\hline \multirow[t]{2}{*}{ Size $(\mathrm{cm})$} & $\leq 5.0$ & $54.0(51.3-55.9)$ & $56.1(54.6-57.2)$ & $0.737(0.389-1.396)$ & 0.347 & 0.154 \\
\hline & $>5.0$ & $53.7(50.4-55.8)$ & $56.3(54.4-57.5)$ & $0.638(0.289-1.408)$ & 0.262 & \\
\hline \multirow[t]{2}{*}{ Differentiation } & Well-moderate & $53.9(51.9-55.4)$ & $56.3(55.1-57.2)$ & $0.685(0.406-1.157)$ & 0.154 & 0.548 \\
\hline & Poor & $52.0(43.1-56.2)$ & $54.7(47.5-58.1)$ & $0.625(0.139-2.805)$ & 0.535 & \\
\hline \multirow[t]{2}{*}{ T category } & 3 & $56.4(54.1-58.0)$ & $57.6(55.4-58.7)$ & $0.797(0.307-2.069)$ & 0.640 & 0.377 \\
\hline & 4 & $51.8(48.7-54.0)$ & $55.6(54.2-56.7)$ & $0.579(0.326-1.030)$ & 0.059 & \\
\hline \multirow[t]{2}{*}{$\mathrm{CEA}^{\mathrm{d}}(\mathrm{ng} / \mathrm{mL})$} & $<5$ & $54.6(51.9-56.6)$ & $56.8(55.3-57.8)$ & $0.774(0.376-1.596)$ & 0.487 & 0.554 \\
\hline & $\geq 5$ & $53.5(50.2-55.7)$ & $55.1(52.6-56.8)$ & $0.682(0.300-1.549)$ & 0.357 & \\
\hline \multirow[t]{2}{*}{ Examined lymph nodes } & $<12$ & $52.0(47.8-54.9)$ & $53.6(50.4-55.7)$ & $0.906(0.407-2.018)$ & 0.810 & 0.517 \\
\hline & $\geq 12$ & $54.4(52.2-56.1)$ & $57.1(55.9-57.9)$ & $0.590(0.316-1.102)$ & 0.094 & \\
\hline \multirow[t]{2}{*}{$P L R^{e}$} & $\leq 130$ & $56.0(53.7-57.6)$ & $56.0(54.4-57.1)$ & $1.016(0.494-2.087)$ & 0.967 & 0.116 \\
\hline & $>130$ & $51.3(48.2-53.8)$ & $56.5(54.9-57.8)$ & $0.440(0.217-0.893)$ & 0.019 & \\
\hline
\end{tabular}

a $P$ value of the log-rank test

b RMST: the restricted mean survival time

' HR: Hazard Ratio, chemotherapy patients vs. non-chemotherapy patients

d CEA: carcinoembryonic antigen

e PLR: platelet to lymphocyte ratio

limitations mentioned above in our following prospective research.

To date, many studies have been conducted to explore the roles of lymphocytes and platelets in tumor progression. Platelets promote angiogenesis, adhesion, and invasion by secreting angiogenic and tumor growth factors, such as transforming growth factor-beta (TGF $\beta$ ) and vascular epidermal growth factor (VEGF), in a tumor environment [45-47]. Platelets have also been demonstrated to prevent the killing of tumor cells by natural killer cells [48]. Furthermore, platelets promote other immune cells, such as lymphocytes and neutrophils, to infiltrate into tumor tissues and trigger further inflammatory progress by releasing chemokines and cytokines [49]. Consequently, high levels of platelets partly reflect systemic inflammation and increased metastization of neoplastic cells $[50,51]$. Lymphocytes, the main components of the immune defense against malignancy of the host, can induce cytotoxic cell death and inhibit tumor cell proliferation and migration [52, 53]. Therefore, low levels of lymphocyte partly reflect an impaired activation of adaptive immunity and poor nutritional status [54, 55]. The studies above did not directly elaborate on the mechanisms of lymphocytes and platelets in chemotherapy. However, they provided ideas for our research.

We suggest three possible explanations for the significant association between elevated PLR and effective chemotherapy treatment shown in our study. First, previous clinical studies have demonstrated that patients with CRC with elevated PLR may have a poorer prognosis and shorter postoperative survival time than other patients [19, 40-44]. Because high-risk patients usually require additional therapy, this aspect may partly explain why this group of patients obtain additional survival benefits from chemotherapy. Second, platelets have been demonstrated to be critical for maintaining tumor vascular generation and integrity [56]. Furthermore, high platelets may be associated with a rich network of tumor vessels and increased transport of chemotherapeutic agents into tumors, thus leading to effective 

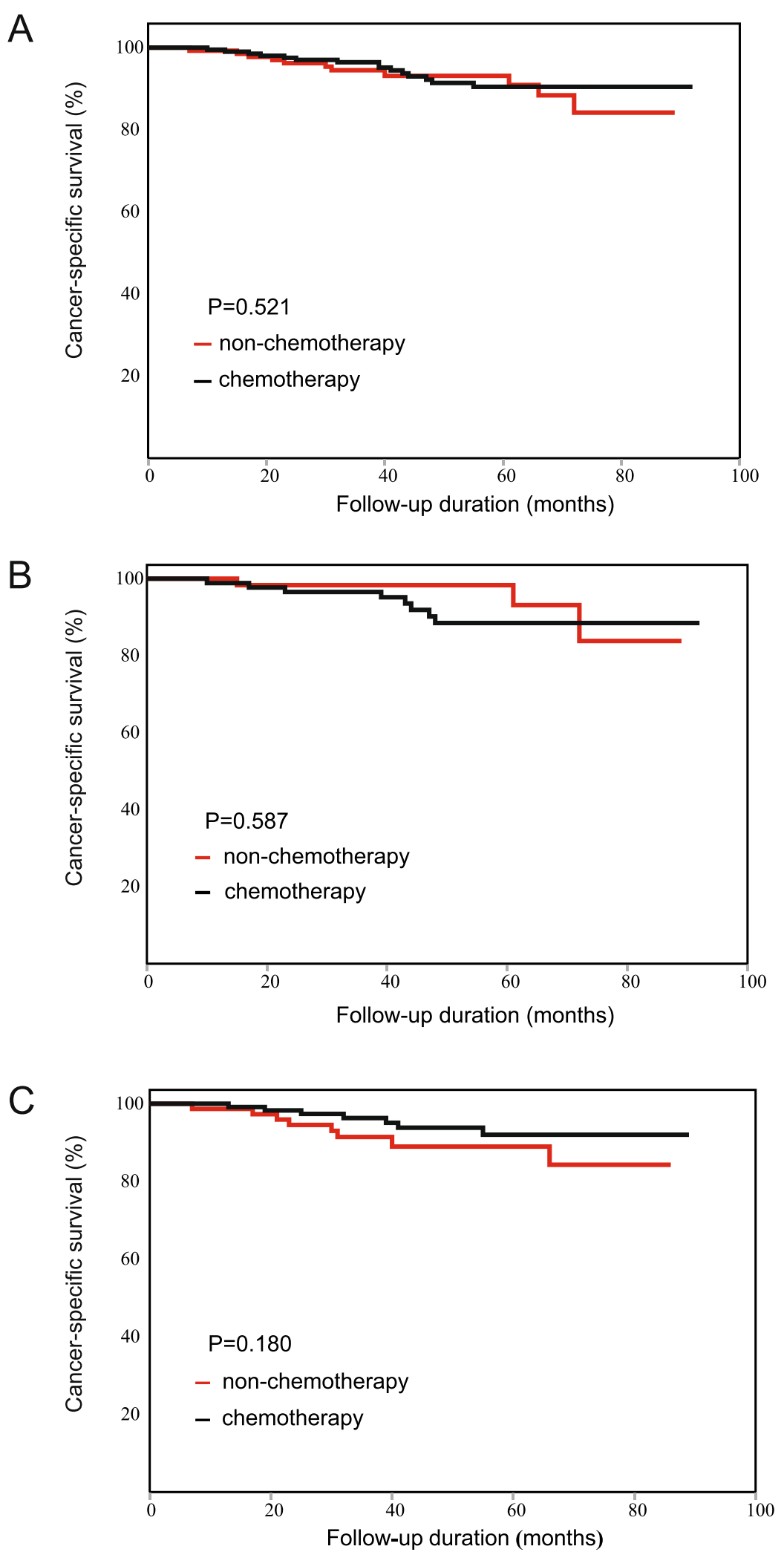

Fig. 7 Kaplan-Meier CSS curve of patients with stage II colon cancer. (A) The result of all patients. (B) The result of the low-PLR subgroup. (C) The result of the high-PLR subgroup 


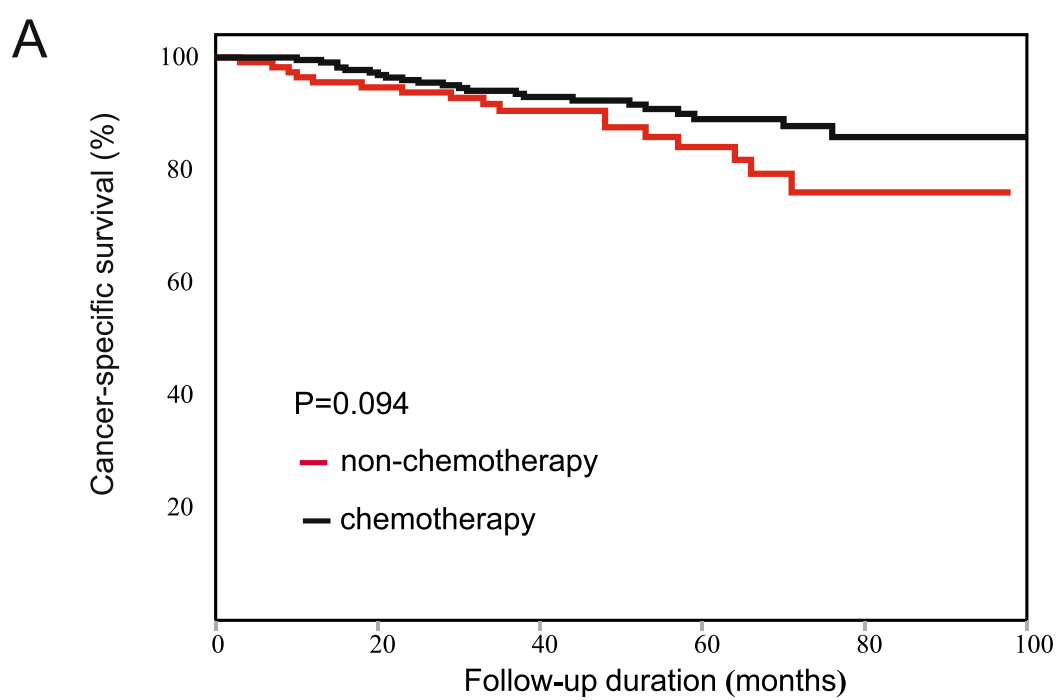

B

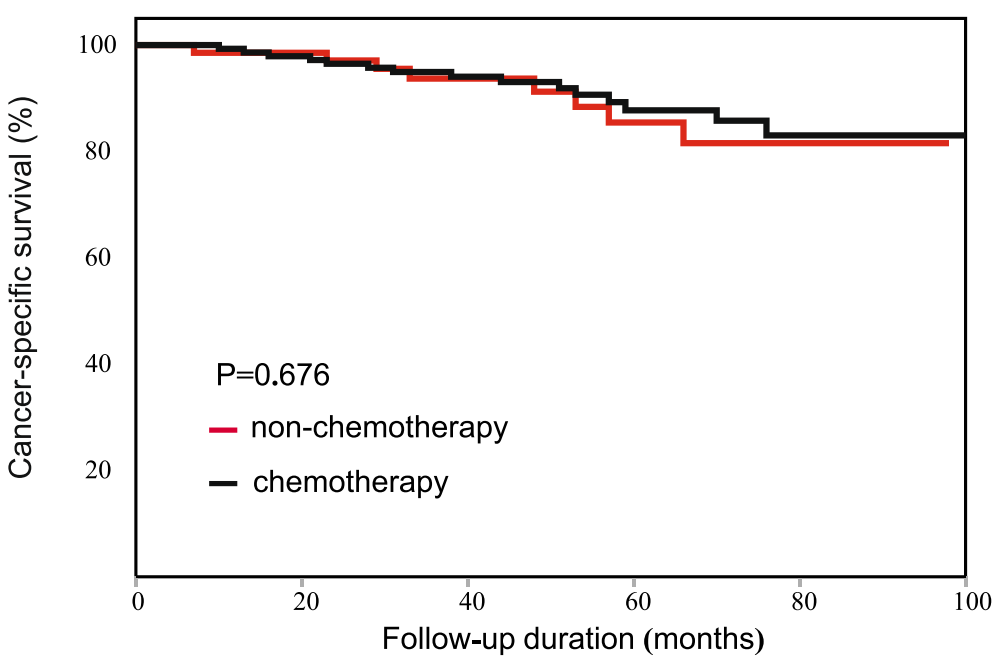

C

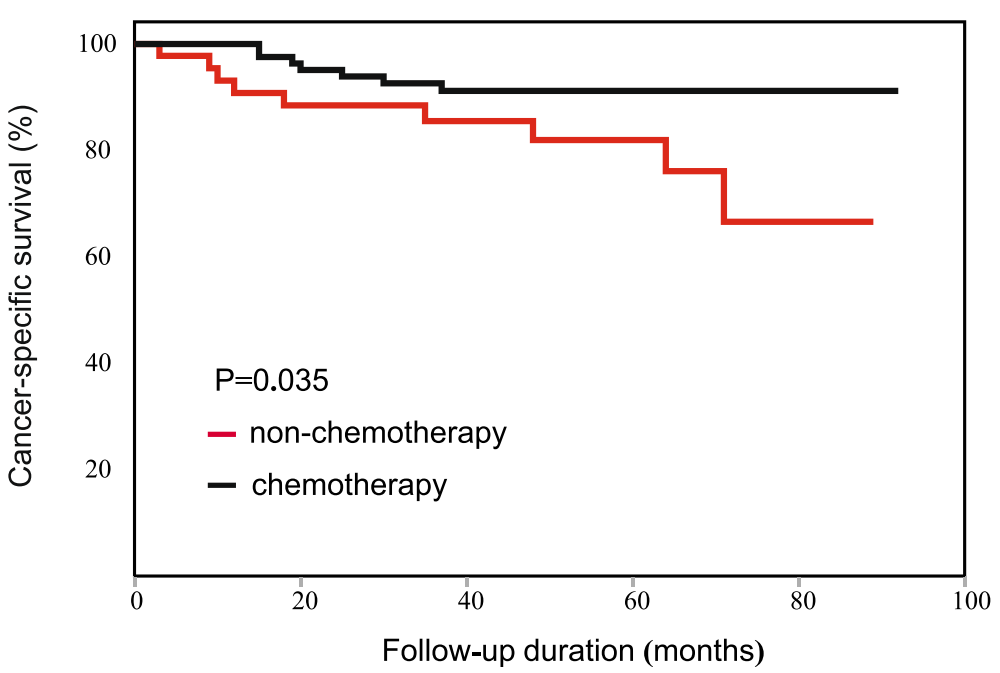

Fig. 8 Kaplan-Meier CSS curve of patients with stage II rectal cancer. (A) The result of all patients. (B) The result of the low-PLR subgroup. (C) The result of the high-PLR subgroup 
Table 9 CSS analysis for patients with colon cancer

\begin{tabular}{|c|c|c|c|c|c|c|}
\hline \multirow[t]{2}{*}{ Characteristics } & & \multicolumn{2}{|l|}{$\mathrm{RMST}^{\mathrm{b}}(95 \% \mathrm{Cl})$} & \multirow[t]{2}{*}{$\mathrm{HR}^{\mathrm{c}}(95 \% \mathrm{Cl})$} & \multirow[t]{2}{*}{ Pvalue $^{a}$} & \multirow[t]{2}{*}{ Interaction $\mathrm{p}$} \\
\hline & & Non-chemotherapy & Chemotherapy & & & \\
\hline Total & - & $53.8(51.7-55.3)$ & $56.2(50.1-57.1)$ & $0.775(0.355-1.691)$ & 0.521 & - \\
\hline \multirow[t]{2}{*}{ Sex } & Male & $53.2(50.7-55.3)$ & $55.9(54.4-57.1)$ & $0.748(0.259-2.164)$ & 0.591 & 0.805 \\
\hline & Female & $54.5(51.3-56.5)$ & $56.8(55.0-58.0)$ & $0.819(0.260-2.585)$ & 0.733 & \\
\hline \multirow[t]{5}{*}{ Age (years) } & $\leq 55$ & $54.3(47.9-57.4)$ & $56.3(54.2-57.7)$ & $0.384(0.074-1.999)$ & 0.237 & 0.371 \\
\hline & $56-60$ & $55.4(47.4-58.5)$ & $56.8(54.2-58.3)$ & $2.720(0.001-16.94)$ & 0.510 & \\
\hline & $61-65$ & $53.3(46.5-57.0)$ & $55.7(52.8-57.4)$ & $1.375(0.159-11.91)$ & 0.772 & \\
\hline & $66-70$ & $53.2(48.2-56.3)$ & $57.3(53.7-58.8)$ & $0.015(0.001-19.84)$ & 0.023 & \\
\hline & $>70$ & $53.6(50.6-55.8)$ & $54.6(50.0-57.2)$ & $2.409(0.486-11.96)$ & 0.266 & \\
\hline \multirow[t]{2}{*}{ Size $(\mathrm{cm})$} & $\leq 5.0$ & $54.0(51.3-55.9)$ & $56.1(54.6-57.2)$ & $1.089(0.364-3.259)$ & 0.878 & 0.294 \\
\hline & $>5.0$ & $53.7(50.4-55.8)$ & $56.3(54.4-57.5)$ & $0.554(0.178-1.721)$ & 0.300 & \\
\hline \multirow[t]{2}{*}{ Differentiation } & Well-moderate & $53.9(51.9-55.4)$ & $56.3(55.1-57.2)$ & $0.777(0.332-1.822)$ & 0.561 & 0.669 \\
\hline & Poor & $52.0(43.1-56.2)$ & $54.7(47.5-58.1)$ & $0.894(0.125-6.367)$ & 0.911 & \\
\hline \multirow[t]{2}{*}{ T category } & 3 & $56.4(54.1-58.0)$ & $57.6(55.4-58.7)$ & $0.827(0.137-4.990)$ & 0.836 & 0.616 \\
\hline & 4 & $51.8(48.7-54.0)$ & $55.6(54.2-56.7)$ & $0.717(0.302-1.705)$ & 0.450 & \\
\hline \multirow[t]{2}{*}{$\mathrm{CEA}^{\mathrm{d}}(\mathrm{ng} / \mathrm{mL})$} & $<5$ & $54.6(51.9-56.6)$ & $56.8(55.3-57.8)$ & $0.721(0.228-2.280)$ & 0.576 & 0.663 \\
\hline & $\geq 5$ & $53.5(50.2-55.7)$ & $55.1(52.6-56.8)$ & $1.047(0.294-3.726)$ & 0.944 & \\
\hline \multirow[t]{2}{*}{ Examined lymph nodes } & $<12$ & $52.0(47.8-54.9)$ & $53.6(50.4-55.7)$ & $0.857(0.245-2.996)$ & 0.809 & 0.962 \\
\hline & $\geq 12$ & $54.4(52.2-56.1)$ & $57.1(55.9-57.9)$ & $0.860(0.311-2.376)$ & 0.771 & \\
\hline \multirow[t]{2}{*}{$\mathrm{PLR}^{\mathrm{e}}$} & $\leq 130$ & $56.0(53.7-57.6)$ & $56.0(54.4-57.1)$ & $1.443(0.381-5.464)$ & 0.587 & 0.245 \\
\hline & $>130$ & $51.3(48.2-53.8)$ & $56.5(54.9-57.8)$ & $0.506(0.183-1.397)$ & 0.180 & \\
\hline
\end{tabular}

a value of the log-rank test

${ }^{b}$ RMST: the restricted mean survival time

' HR: Hazard Ratio, chemotherapy patients vs. non-chemotherapy patients

${ }^{d}$ CEA: carcinoembryonic antigen

e PLR: platelet to lymphocyte ratio

Table 10 CSS analysis for patients with rectal cancer

\begin{tabular}{|c|c|c|c|c|c|c|}
\hline \multirow[t]{2}{*}{ Characteristics } & & \multicolumn{2}{|l|}{$\mathrm{RMST}^{\mathrm{b}}(95 \% \mathrm{Cl})$} & \multirow[t]{2}{*}{$\mathrm{HR}^{\mathrm{c}}(95 \% \mathrm{Cl})$} & \multirow[t]{2}{*}{$P_{\text {value }}{ }^{a}$} & \multirow[t]{2}{*}{ Interaction $\mathrm{p}$} \\
\hline & & Non-chemotherapy & Chemotherapy & & & \\
\hline Total & - & $53.8(51.7-55.3)$ & $56.2(50.1-57.1)$ & $0.586(0.311-1.105)$ & 0.094 & - \\
\hline \multirow[t]{2}{*}{ Sex } & Male & $53.2(50.7-55.3)$ & $55.9(54.4-57.1)$ & $0.515(0.251-1.056)$ & 0.065 & 0.488 \\
\hline & Female & $54.5(51.3-56.5)$ & $56.8(55.0-58.0)$ & $0.989(0.245-3.983)$ & 0.987 & \\
\hline \multirow[t]{5}{*}{ Age (years) } & $\leq 55$ & $54.3(47.9-57.4)$ & $56.3(54.2-57.7)$ & $0.965(0.205-4.548)$ & 0.964 & 0.630 \\
\hline & $56-60$ & $55.4(47.4-58.5)$ & $56.8(54.2-58.3)$ & $0.463(0.085-2.527)$ & 0.362 & \\
\hline & $61-65$ & $53.3(46.5-57.0)$ & $55.7(52.8-57.4)$ & $0.466(0.109-1.985)$ & 0.290 & \\
\hline & $66-70$ & $53.2(48.2-56.3)$ & $57.3(53.7-58.8)$ & $0.329(0.046-2.369)$ & 0.246 & \\
\hline & $>70$ & $53.6(50.6-55.8)$ & $54.6(50.0-57.2)$ & $0.833(0.221-3.143)$ & 0.787 & \\
\hline \multirow[t]{2}{*}{ Size $(\mathrm{cm})$} & $\leq 5.0$ & $54.0(51.3-55.9)$ & $56.1(54.6-57.2)$ & $0.575(0.261-1.269)$ & 0.165 & 0.342 \\
\hline & $>5.0$ & $53.7(50.4-55.8)$ & $56.3(54.4-57.5)$ & $0.711(0.232-2.177)$ & 0.549 & \\
\hline \multirow[t]{2}{*}{ Differentiation } & Well-moderate & $53.9(51.9-55.4)$ & $56.3(55.1-57.2)$ & $0.608(0.313-1.180)$ & 0.137 & 0.900 \\
\hline & Poor & $52.0(43.1-56.2)$ & $54.7(47.5-58.1)$ & $0.372(0.033-4.146)$ & 0.403 & \\
\hline \multirow[t]{2}{*}{ T category } & 3 & $56.4(54.1-58.0)$ & $57.6(55.4-58.7)$ & $0.792(0.255-2.456)$ & 0.685 & 0.376 \\
\hline & 4 & $51.8(48.7-54.0)$ & $55.6(54.2-56.7)$ & $0.465(0.215-1.003)$ & 0.046 & \\
\hline \multirow[t]{2}{*}{$C E A^{d}(n g / m L)$} & $<5$ & $54.6(51.9-56.6)$ & $56.8(55.3-57.8)$ & $0.792(0.312-2.013)$ & 0.624 & 0.681 \\
\hline & $\geq 5$ & $53.5(50.2-55.7)$ & $55.1(52.6-56.8)$ & $0.457(0.153-1.366)$ & 0.151 & \\
\hline \multirow[t]{2}{*}{ Examined lymph nodes } & $<12$ & $52.0(47.8-54.9)$ & $53.6(50.4-55.7)$ & $0.950(0.324-2.786)$ & 0.926 & 0.249 \\
\hline & $\geq 12$ & $54.4(52.2-56.1)$ & $57.1(55.9-57.9)$ & $0.444(0.199-0.990)$ & 0.041 & \\
\hline \multirow[t]{2}{*}{$\mathrm{PLR}^{\mathrm{e}}$} & $\leq 130$ & $56.0(53.7-57.6)$ & $56.0(54.4-57.1)$ & $0.833(0.352-1.967)$ & 0.676 & 0.202 \\
\hline & $>130$ & $51.3(48.2-53.8)$ & $56.5(54.9-57.8)$ & $0.360(0.134-0.969)$ & 0.035 & \\
\hline
\end{tabular}

${ }^{\mathrm{a}} \mathrm{P}$ value of the log-rank test

${ }^{b}$ RMST: the restricted mean survival time

c HR: Hazard Ratio, chemotherapy patients vs. non-chemotherapy patients

${ }^{d}$ CEA: carcinoembryonic antigen

e PLR: platelet to lymphocyte ratio 

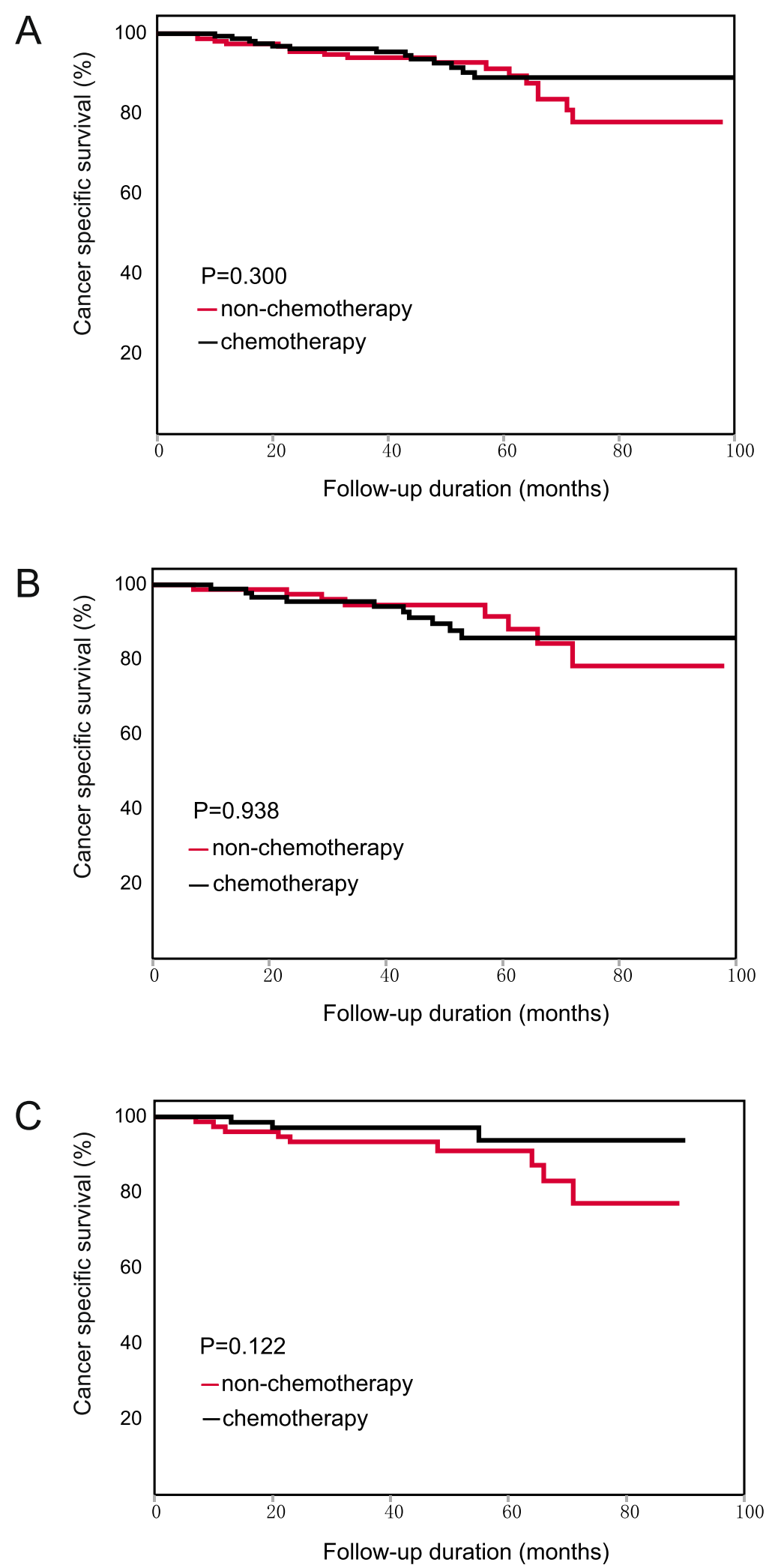

Fig. 9 Kaplan-Meier CSS curve of patients with stage II CRC after PSM. (A) The result of all patients. (B) The result of the low-PLR subgroup. (C) The result of the high-PLR subgroup 
Table 11 CSS analysis for patients after PSM

\begin{tabular}{|c|c|c|c|c|c|c|}
\hline \multirow[t]{2}{*}{ Characteristics } & & \multicolumn{2}{|l|}{$\mathrm{RMST}^{\mathrm{b}}(95 \% \mathrm{Cl})$} & \multirow[t]{2}{*}{$\mathrm{HR}^{\mathrm{c}}(95 \% \mathrm{Cl})$} & \multirow[t]{2}{*}{$P$ value $^{a}$} & \multirow[t]{2}{*}{ Interaction $p$} \\
\hline & & Non-chemotherapy & Chemotherapy & & & \\
\hline Total & - & $53.3(51.0-55.1)$ & $56.0(53.8-57.5)$ & $0.684(0.332-1.409)$ & 0.300 & - \\
\hline \multirow[t]{2}{*}{ Sex } & Male & $52.0(48.4-54.6)$ & $55.9(53.2-57.7)$ & $0.420(0.169-1.042)$ & 0.053 & 0.026 \\
\hline & Female & $55.0(51.1-57.3)$ & $56.1(52.2-57.9)$ & $1.926(0.478-7.762)$ & 0.349 & \\
\hline \multirow[t]{5}{*}{ Age (years) } & $\leq 55$ & $53.8(46.5-57.4)$ & $56.6(50.4-58.9)$ & $0.435(0.079-2.388)$ & 0.324 & 0.196 \\
\hline & $56-60$ & $54.6(45.3-58.2)$ & $57.1(49.9-59.2)$ & $0.458(0.041-5.054)$ & 0.513 & \\
\hline & $61-65$ & $53.2(46.3-57.0)$ & $55.6(48.5-58.1)$ & $0.789(0.158-3.949)$ & 0.772 & \\
\hline & $66-70$ & $54.2(48.5-57.3)$ & $57.5(52.7-59.1)$ & $0.182(0.020-1.645)$ & 0.086 & \\
\hline & $>70$ & $52.0(47.2-55.3)$ & $53.9(48.5-56.5)$ & $1.660(0.468-5.887)$ & 0.427 & \\
\hline \multirow[t]{2}{*}{ Location } & Rectum & $52.4(48.7-54.9)$ & $54.6(51.3-56.8)$ & $0.738(0.297-1.836)$ & 0.511 & 0.797 \\
\hline & Colon & $54.5(50.3-56.8)$ & $57.5(54.8-58.8)$ & $0.634(0.192-2.087)$ & 0.449 & \\
\hline \multirow[t]{2}{*}{ Size $(\mathrm{cm})$} & $\leq 5.0$ & $54.3(50.6-56.5)$ & $56.7(54.0-58.2)$ & $0.846(0.295-2.425)$ & 0.756 & 0.116 \\
\hline & $>5.0$ & $52.6(48.8-55.5)$ & $55.1(51.6-57.3)$ & $0.641(0.228-1.802)$ & 0.395 & \\
\hline \multirow[t]{2}{*}{ Differentiation } & Well-moderate & $53.5(50.8-55.5)$ & $56.1(54.2-57.5)$ & $0.703(0.329-1.504)$ & 0.361 & 0.864 \\
\hline & Poor & $50.5(36.0-56.7)$ & $53.8(38.2-58.6)$ & $0.574(0.050-6.560)$ & 0.651 & \\
\hline \multirow[t]{2}{*}{ T category } & 3 & $58.1(54.1-59.4)$ & $57.3(54.3-58.9)$ & $3.306(0.367-29.738)$ & 0.258 & 0.042 \\
\hline & 4 & $50.9(47.3-53.6)$ & $55.2(52.3-57.0)$ & $0.517(0.228-1.172)$ & 0.107 & \\
\hline \multirow[t]{2}{*}{$\mathrm{CEA}^{\mathrm{d}}(\mathrm{ng} / \mathrm{mL})$} & $<5$ & $55.2(51.9-57.2)$ & $57.3(54.3-58.7)$ & $0.785(0.239-2.573)$ & 0.688 & 0.897 \\
\hline & $\geq 5$ & $52.4(47.5-55.8)$ & $55.0(51.4-57.2)$ & $0.667(0.203-2.195)$ & 0.502 & \\
\hline \multirow[t]{2}{*}{ Examined lymph nodes } & $<12$ & $50.7(43.8-54.8)$ & $51.7(45.5-55.2)$ & $1.620(0.487-5.393)$ & 0.427 & 0.107 \\
\hline & $\geq 12$ & $54.1(51.1-56.0)$ & $57.5(55.6-58.7)$ & $0.359(0.128-1.007)$ & 0.042 & \\
\hline \multirow[t]{2}{*}{$P L R^{e}$} & $\leq 130$ & $55.3(51.8-57.4)$ & $54.9(51.9-56.8)$ & $0.963(0.379-2.449)$ & 0.938 & 0.231 \\
\hline & $>130$ & $51.3(47.4-54.1)$ & $57.6(54.7-58.9)$ & $0.372(0.100-1.374)$ & 0.122 & \\
\hline
\end{tabular}

${ }^{\mathrm{a}} \mathrm{P}$ value of the log-rank test

${ }^{b}$ RMST: the restricted mean survival time

' HR: Hazard Ratio, chemotherapy patients vs. non-chemotherapy patients

d CEA: carcinoembryonic antigen

e PLR: platelet to lymphocyte ratio

chemotherapy treatment. In fact, improving vascular function has long been discussed as a possibility to improve the treatment effect of chemotherapy [57]. Third, myelosuppression, as a common side effect of chemotherapy, is an important factor for the continuation of chemotherapy in clinical practice. In chemotherapy for CRC, two frequently used agents, oxaliplatin and capecitabine, have been demonstrated to induce myelosuppression, including thrombocytopenia [58-61]. Patients with elevated PLR may have greater tolerance to chemotherapy than other patients, thus allowing them to receive longer and larger doses of chemotherapy. This aspect may explain the association between elevated PLR and effective chemotherapy treatment.

Our results indicated a positive association between elevated PLR and effective chemotherapy treatment in patients with stage II CRC. PLR showed potential as a practical, inexpensive, highly reliable and easily available marker to predict the effect of chemotherapy. However, the potential mechanisms and the specific predictive ability of PLR should be validated in further prospective, larger population and multi-center studies.

\section{Conclusions}

In conclusion, our study indicated that PLR was significantly associated with the effects of chemotherapy in patients with stage II CRC. Patients with elevated PLR > 130 obtained substantial survival benefits from chemotherapy, whereas patients with low PLR $\leq 130$ did not. PLR can be used as an effective inflammatory marker to predict the effects of chemotherapy and to distinguish the population in which chemotherapy is effective among patients with stage II CRC.

\section{Abbreviations}

CRC: colorectal cancer; CEA: carcinoembryonic antigen

CCVD: cerebrovascular and cardiovascular diseases; PLR: platelet to lymphocyte ratio; NLR: neutrophil to lymphocyte ratio; LMR: lymphocyte to monocyte ratio; PNI: prognostic nutritional index; STEPP: Subpopulation 
Treatment Effect Pattern Plot; OS: overall survival; HR: Hazard Ratio; RMST: restricted mean survival time; PSM: Propensity Score Matching; TGF $\beta$ : transforming growth factor-beta; VEGF: vascular epidermal growth factor; $\mathrm{Cl}$ : Confidence interval

\section{Supplementary Information}

The online version contains supplementary material available at https://doi. org/10.1186/s12885-021-08521-0

Additional file 1. The clinicopathological characteristics of each patient before PSM.

Additional file 2. The clinicopathological characteristics of each patient after PSM.

\section{Acknowledgements}

We thank Yiducloud (Beijing) Technology Ltd. for supporting part of the data extraction and processing. The corresponding author had full access to all the data and analyses.

\section{Authors' contributions}

PG and ZW formulated the research question. XC and QC collected the bulk of data profiles, YF drafted the full manuscript. YS provided substantial input in planning and revising the manuscript. PG provided statistical support and made revision to the results section of the manuscript. $\mathrm{XH}$ and $\mathrm{XC}$ contributed revisions to the introduction and the discussion. LX conducted analyses and sorted parts of the methods section. ZW played a crucial role in the design of the research and provided revision to this text. All authors contributed to manuscript revision, read and approved the submitted version.

\section{Funding}

This work was supported by the grants from Natural Science Foundation of Liaoning Province of China (2019-MS-390), Liaoning Province Central Guided Local Science and Technology Development Special Fund (2018107004), Overseas Training Program for Higher Learning Institutions of Liaoning Province (2019GJWYB022) and Major Scientific and Technological Special Project of Liaoning Province of China (2019JH1/10300007).

\section{Availability of data and materials}

All data generated and analyzed during this study are included in this published article and its supplementary information files.

\section{Declarations}

\section{Ethics approval and consent to participate}

The study involving human participants was reviewed and approved by the ethics committees of the First Affiliated Hospital of China Medical University. The patients provided their written informed consent to participate in this study.

\section{Consent for publication}

Not applicable.

\section{Competing interests}

The authors declare that they have no competing interests

Received: 16 July 2020 Accepted: 17 June 2021

Published online: 08 July 2021

\section{References}

1. Bray F, Ferlay J, Soerjomataram I, Siegel RL, Torre LA, Jemal A. Global cancer statistics 2018: GLOBOCAN estimates of incidence and mortality worldwide for 36 cancers in 185 countries. CA Cancer J Clin. 2018;68(6):394-424. https://doi.org/10.3322/caac.21492.

2. Sargent D, Sobrero A, Grothey A, O'Connell MJ, Buyse M, Andre T, et al. Evidence for cure by adjuvant therapy in colon cancer: observations based on individual patient data from 20,898 patients on 18 randomized trials. J Clin Oncol. 2009;27(6):872-7. https://doi.org/10.1200/jco.2008.19.5362.
3. Booth CM, Nanji S, Wei X, Peng Y, Biagi JJ, Hanna TP, et al. Use and effectiveness of adjuvant chemotherapy for stage III Colon Cancer: a population-based study. J National Comprehensive Cancer Network. 2016; 14(1):47-56. https://doi.org/10.6004/jnccn.2016.0006.

4. Andre T, de Gramont A, Vernerey D, Chibaudel B, Bonnetain F, TijerasRaballand A, et al. Adjuvant fluorouracil, Leucovorin, and Oxaliplatin in stage II to III Colon Cancer: updated 10-year survival and outcomes according to BRAF mutation and mismatch repair status of the MOSAIC study. J Clin Oncol. 2015;33(35):4176-87. https://doi.org/10.1200/jco.2015.63.4238.

5. Shah MA, Renfro LA, Allegra CJ, Andre T, de Gramont A, Schmoll HJ, et al. Impact of patient factors on recurrence risk and time dependency of Oxaliplatin benefit in patients with Colon Cancer: analysis from modern-era adjuvant studies in the adjuvant Colon Cancer end points (ACCENT) database. J Clin Oncol. 2016;34(8):843-53. https://doi.org/10.1200/jco.2015. 63.0558.

6. Gray R, Barnwell J, McConkey C, Hills RK, Williams NS, Kerr DJ. Adjuvant chemotherapy versus observation in patients with colorectal cancer: a randomised study. Lancet (London, England) 370. 2020-9. 2007;370(9604): 2020-9. https://doi.org/10.1016/s0140-6736(07)61866-2

7. Wilkinson NW, Yothers G, Lopa S, Costantino JP, Petrelli NJ, Wolmark N. Long-term survival results of surgery alone versus surgery plus 5-fluorouracil and leucovorin for stage II and stage III colon cancer: pooled analysis of NSABP C-01 through C-05. A baseline from which to compare modern adjuvant trials. Ann Surg Oncol. 2010;17(4):959-66. https://doi.org/10.1245/ s10434-009-0881-y.

8. Costas-Chavarri A, Nandakumar G, Temin S, Lopes G, Cervantes A, Cruz Correa M, et al. Treatment of patients with early-stage colorectal Cancer: ASCO resource-stratified guideline. J Global Oncol. 2019;5(5):1-19. https:// doi.org/10.1200/jgo.18.00214

9. Kannarkatt J, Joseph J, Kurniali PC, Al-Janadi A, Hrinczenko B. Adjuvant chemotherapy for stage II Colon Cancer: a clinical dilemma. J Oncol Pract. 2017;13(4):233-41. https://doi.org/10.1200/jop.2016.017210.

10. Boland GM, Chang GJ, Haynes AB, Chiang YJ, Chagpar R, Xing Y, et al. Association between adherence to National Comprehensive Cancer Network treatment guidelines and improved survival in patients with colon cancer. Cancer. 2013;119(8):1593-601. https://doi.org/10.1002/cncr.27935.

11. Casadaban L, Rauscher G, Aklilu M, Villenes D, Freels S, Maker AV. Adjuvant chemotherapy is associated with improved survival in patients with stage II colon cancer. Cancer. 2016;122(21):3277-87. https://doi. org/10.1002/cncr.30181

12. Hines RB, Barrett A, Twumasi-Ankrah P, Broccoli D, Engelman KK, Baranda J, et al. Predictors of guideline treatment nonadherence and the impact on survival in patients with colorectal cancer. J National Comprehensive Cancer Network. 2015;13(1):51-60. https://doi.org/10.6004/jnccn.2015.0008.

13. Benson AB, Venook AP, Al-Hawary MM, Cederquist L, Chen YJ, Ciombor KK, et al. NCCN guidelines insights: Colon Cancer, version 2.2018. J National Comprehensive Cancer Network. 2018;16(4):359-69. https://doi.org/10.6004/ jnccn.2018.0021

14. Jiang J, Ma T, Xi W, Yang C, Wu J, Zhou C, et al. Pre-treatment inflammatory biomarkers predict early treatment response and favorable survival in patients with metastatic colorectal cancer who underwent first line cetuximab plus chemotherapy. Cancer Manag Res. 2019;11:8657-68. https:// doi.org/10.2147/cmar.S211089.

15. Kim IH, Lee JE, Yang JH, Jeong JW, Ro S, Lee MA. Clinical significance of changes in systemic inflammatory markers and carcinoembryonic antigen levels in predicting metastatic colorectal cancer prognosis and chemotherapy response. Asia Pac J Clin Oncol. 2018;14(3):239-46. https:// doi.org/10.1111/ajco.12784

16. M. Shibutani, H. Nagahara, T. Fukuoka, Y. Iseki, K. Hirakawa, and M. Ohira. (2019). Efficacy of adjuvant chemotherapy according to the classification of recurrence risk based on systemic inflammatory markers in patients with liver metastases of colorectal Cancer. Anticancer research 39.5039-5045. Doi: https://doi.org/10.21873/anticanres.13695.

17. Li MX, Liu XM, Zhang XF, Zhang JF, Wang WL, Zhu Y, et al. Prognostic role of neutrophil-to-lymphocyte ratio in colorectal cancer: a systematic review and meta-analysis. Int J Cancer. 2014;134(10):2403-13. https://doi.org/10.1 002/ijc.28536

18. Sun J, Chen $X$, Gao $P$, Song $Y$, Huang $X$, Yang $Y$, et al. Can the neutrophil to lymphocyte ratio be used to determine gastric Cancer treatment outcomes? A systematic review and meta-analysis. Dis Markers. 2016;2016: 7862469-10. https://doi.org/10.1155/2016/7862469. 
19. C. Lu, P. Gao, Y. Yang, X. Chen, L. Wang, D. Yu, et al. (2017). Prognostic evaluation of platelet to lymphocyte ratio in patients with colorectal cancer. Oncotarget 8. 86287-86295. Doi: https://doi.org/10.18632/oncota rget.21141.

20. Yang Y, Gao P, Song Y, Sun J, Chen X, Zhao J, et al. The prognostic nutritional index is a predictive indicator of prognosis and postoperative complications in gastric cancer: a meta-analysis. Eur J Surgical Oncol. 2016; 42(8):1176-82. https://doi.org/10.1016/j.ejso.2016.05.029.

21. Chan JC, Chan DL, Diakos Cl, Engel A, Pavlakis N, Gill A, et al. The lymphocyte-to-monocyte ratio is a superior predictor of overall survival in comparison to established biomarkers of Resectable colorectal Cancer. Ann Surg. 2017;265(3):539-46. https://doi.org/10.1097/sla.0000000000001743.

22. de Visser KE, Jonkers J. Towards understanding the role of cancer-associated inflammation in chemoresistance. Curr Pharm Des. 2009;15(16):1844-53. https://doi.org/10.2174/138161209788453239.

23. Jinushi M, Komohara Y. Tumor-associated macrophages as an emerging target against tumors: creating a new path from bench to bedside. Biochim Biophys Acta. 2015;1855(2):123-30. https://doi.org/10.1016/j.bbcan.2015.01. 002.

24. Sun $H, H u P, D u J$, Wang $X$. Predictive value of inflammatory indexes on the chemotherapeutic response in patients with unresectable lung cancer: a retrospective study. Oncol Lett. 2018;15:4017-25. https://doi.org/10.3892/ol.2 018.7781.

25. Sanderson RD, Elkin M, Rapraeger AC, Ilan N, Vlodavsky I. Heparanase regulation of cancer, autophagy and inflammation: new mechanisms and targets for therapy. FEBS J. 2017;284(1):42-55. https://doi.org/10.1111/febs.13 932.

26. Olive KP. Fanning the flames of Cancer Chemoresistance: inflammation and anticancer therapy. J Oncol Pract. 2017;13(3):181-3. https://doi.org/10.1200/ jop.2017.021154.

27. T. Onodera, N. Goseki, and G. Kosaki. (1984). [Prognostic nutritional index in gastrointestinal surgery of malnourished cancer patients]. Nihon Geka Gakkai zasshi 85. 1001-5.

28. M. Bonetti, and R.D. Gelber. (2004). Patterns of treatment effects in subsets of patients in clinical trials. Biostatistics (Oxford, England) 5. 465-81. doi: https://doi.org/10.1093/biostatistics/5.3.465.

29. Lazar AA, Cole BF, Bonetti M, Gelber RD. Evaluation of treatment-effect heterogeneity using biomarkers measured on a continuous scale: subpopulation treatment effect pattern plot. J Clin Oncol. 2010;28(29):4539_ 44. https://doi.org/10.1200/jco.2009.27.9182.

30. Zhao L, Claggett B, Tian L, Uno H, Pfeffer MA, Solomon SD, et al. On the restricted mean survival time curve in survival analysis. Biometrics. 2016; 72(1):215-21. https://doi.org/10.1111/biom.12384.

31. Wang $X$, Schaubel DE. Modeling restricted mean survival time under general censoring mechanisms. Lifetime Data Anal. 2018;24(1):176-99. https://doi.org/10.1007/s10985-017-9391-6.

32. Little RJ, Rubin DB. Causal effects in clinical and epidemiological studies via potential outcomes: concepts and analytical approaches. Annu Rev Public Health. 2000;21(1):121-45. https://doi.org/10.1146/annurev.publhea Ith.21.1.121.

33. Rubin DB. Estimating causal effects from large data sets using propensity scores. Ann Intern Med. 1997;127(8_Part_2):757-63. https://doi.org/10.7326/ 0003-4819-127-8_part_2-199710151-00064.

34. D'Agostino RB Jr. Propensity score methods for bias reduction in the comparison of a treatment to a non-randomized control group. Stat Med. 1998;17(19):2265-81. https://doi.org/10.1002/(sici)1097-0258(19981015)17:1 9<2265::aid-sim918>3.0.co;2-b.

35. Hochster HS, Hart LL, Ramanathan RK, Childs BH, Hainsworth JD, Cohn AL, et al. Safety and efficacy of oxaliplatin and fluoropyrimidine regimens with or without bevacizumab as first-line treatment of metastatic colorectal cancer: results of the TREE study. J Clin Oncol. 2008;26(21):3523-9. https:// doi.org/10.1200/jco.2007.15.4138.

36. S. Dueland, A.H. Ree, K.K. Groholt, M.G. Saelen, S. Folkvord, K.H. Hole, et al. (2016). Oxaliplatin-containing preoperative therapy in locally advanced rectal Cancer: local response, toxicity and long-term outcome. Clin Oncol (Royal College of Radiologists (Great Britain)) 28. 532-9. doi: https://doi.org/1 0.1016/j.clon.2016.01.014, 28, 8, 532, 539 .

37. C.S. Roxburgh, and D.C. McMillan. (2010). Role of systemic inflammatory response in predicting survival in patients with primary operable cancer. Future Oncol (London, England) 6, 1, 149, 163. doi: https://doi.org/10.2217/ fon.09.136.
38. Yang J, Xu H, Guo X, Zhang J, Ye X, Yang Y, et al. Pretreatment inflammatory indexes as prognostic predictors for survival in colorectal Cancer patients receiving neoadjuvant Chemoradiotherapy. Sci Rep. 2018; 8(1):3044. https://doi.org/10.1038/s41598-018-21093-7.

39. Murata M. Inflammation and cancer. Environ Health Prev Med. 2018;23(1):50. https://doi.org/10.1186/s12199-018-0740-1.

40. Kwon HC, Kim SH, Oh SY, Lee S, Lee JH, Choi HJ, et al. Clinical significance of preoperative neutrophil-lymphocyte versus platelet-lymphocyte ratio in patients with operable colorectal cancer. Biomarkers. 2012;17(3):216-22. https://doi.org/10.3109/1354750X.2012.656705.

41. Ozawa T, Ishihara S, Nishikawa T, Tanaka T, Tanaka J, Kiyomatsu T, et al. The preoperative platelet to lymphocyte ratio is a prognostic marker in patients with stage II colorectal cancer. Int J Colorectal Dis. 2015;30(9):1165-71. https://doi.org/10.1007/s00384-015-2276-9.

42. Szkandera J, Pichler M, Absenger G, Stotz M, Arminger F, Weissmueller M, et al. The elevated preoperative platelet to lymphocyte ratio predicts decreased time to recurrence in colon cancer patients. Am J Surg. 2014; 208(2):210-4. https://doi.org/10.1016/j.amjsurg.2013.10.030.

43. Lee $I H$, Hwang S, Lee SJ, Kang BW, Baek D, Kim HJ, et al. Systemic Inflammatory Response After Preoperative Chemoradiotherapy Can Affect Oncologic Outcomes in Locally Advanced Rectal Cancer. Anticancer Res. 2017;37(3):1459-65. doi: https://doi.org/10.21873/anticanres.11470.

44. You J, Zhu GQ, Xie L, Liu WY, Shi L, Wang OC, et al. Preoperative platelet to lymphocyte ratio is a valuable prognostic biomarker in patients with colorectal cancer. Oncotarget. 2016;7(18):25516-27. doi: https://doi.org/10.1 8632/oncotarget.8334.

45. Labelle M, Begum S, Hynes RO. Direct signaling between platelets and cancer cells induces an epithelial-mesenchymal-like transition and promotes metastasis. Cancer Cell. 2011;20(5):576-90. https://doi.org/10.1016/j.ccr.2011. 09.009.

46. Gay LJ, Felding-Habermann B. Contribution of platelets to tumour metastasis. Nature reviews. Cancer. 2011;11(2):123-34. https://doi.org/10.103 8/nrc3004.

47. Tsuji T, Sawai T, Yamashita H, Takeshita H, Nakagoe T, Shindou H, et al. Platelet-derived endothelial cell growth factor expression is an independent prognostic factor in colorectal cancer patients after curative surgery. Eur J Surgical Oncol. 2004;30(3):296-302. https://doi.org/10.1016/j.ejso.2003.11.019.

48. Palumbo JS, Talmage KE, Massari JV, La Jeunesse CM, Flick MJ, Kombrinck $\mathrm{KW}$, et al. Platelets and fibrin(ogen) increase metastatic potential by impeding natural killer cell-mediated elimination of tumor cells. Blood. 2005; 105(1):178-85. https://doi.org/10.1182/blood-2004-06-2272.

49. Jenne CN, Urrutia R, Kubes P. Platelets: bridging hemostasis, inflammation, and immunity. Int J Lab Hematol. 2013;35(3):254-61. https://doi.org/10.1111/ ijlh.12084.

50. Raungkaewmanee S, Tangjitgamol S, Manusirivithaya S, Srijaipracharoen S, Thavaramara T. Platelet to lymphocyte ratio as a prognostic factor for epithelial ovarian cancer. J Gynecol Oncol. 2012;23(4):265-73. https://doi. org/10.3802/jgo.2012.23.4.265.

51. Roxburgh CS, McMillan DC. Cancer and systemic inflammation: treat the tumour and treat the host. Br J Cancer. 2014;110(6):1409-12. https://doi. org/10.1038/bjc.2014.90

52. De Giorgi U, Mego M, Scarpi E, Giuliano M, Giordano A, Reuben JM, et al. Relationship between lymphocytopenia and circulating tumor cells as prognostic factors for overall survival in metastatic breast cancer. Clin Breast Cancer. 2012;12(4):264-9. https://doi.org/10.1016/j.clbc.2012.04.004.

53. Rosenberg SA. Progress in human tumour immunology and immunotherapy. Nature. 2001;411(6835):380-4. https://doi.org/10.1038/35077246.

54. Wagner DD. New links between inflammation and thrombosis. Arterioscler Thromb Vasc Biol. 2005;25(7):1321-4. https:/doi.org/10.1161/01.Atv.0000166521.90532.44.

55. Gross RL, Newberne PM. Role of nutrition in immunologic function. Physiol Rev. 1980;60(1):188-302. https://doi.org/10.1152/physrev.1980.60.1.188.

56. Volz J, Mammadova-Bach E, Gil-Pulido J, Nandigama R, Remer K, Sorokin L, et al. Inhibition of platelet GPVI induces intratumor hemorrhage and increases efficacy of chemotherapy in mice. Blood. 2019;133(25):2696-706. https://doi.org/10.1182/blood.2018877043.

57. Jain RK. Normalization of tumor vasculature: an emerging concept in antiangiogenic therapy. Science (New York, N.Y.) 307. 58-62. 2005;307(5706): 58-62. https://doi.org/10.1126/science.1104819.

58. Beg MS, Komrokji RS, Ahmed K, Safa MM. Oxaliplatin-induced immune mediated thrombocytopenia. Cancer Chemother Pharmacol. 2008;62(5): 925-7. https://doi.org/10.1007/s00280-007-0675-5. 
59. Curtis BR, Kaliszewski J, Marques MB, Saif MW, Nabelle L, Blank J, et al. Immunemediated thrombocytopenia resulting from sensitivity to oxaliplatin. Am J Hematol. 2006;81(3):193-8. https://doi.org/10.1002/ajh.20516.

60. Ito Y, Kobuchi S, Shimizu R, Katsuyama Y. Pharmacokinetic and toxicodynamic evaluation of oxaliplatin-induced neuropathy and hematological toxicity in rats. Cancer Chemother Pharmacol. 2018;81(1): 155-61. https://doi.org/10.1007/s00280-017-3485-4.

61. Zandvliet AS, Siegel-Lakhai WS, Beijnen JH, Copalu W, Etienne-Grimaldi MC, Milano G, et al. PK/PD model of indisulam and capecitabine: interaction causes excessive myelosuppression. Clin Pharmacol Ther. 2008;83(6):829-39. https://doi.org/10.1038/sj.clpt.6100344.

\section{Publisher's Note}

Springer Nature remains neutral with regard to jurisdictional claims in published maps and institutional affiliations.

Ready to submit your research? Choose BMC and benefit from:

- fast, convenient online submission

- thorough peer review by experienced researchers in your field

- rapid publication on acceptance

- support for research data, including large and complex data types

- gold Open Access which fosters wider collaboration and increased citations

- maximum visibility for your research: over $100 \mathrm{M}$ website views per year

At BMC, research is always in progress.

Learn more biomedcentral.com/submissions 